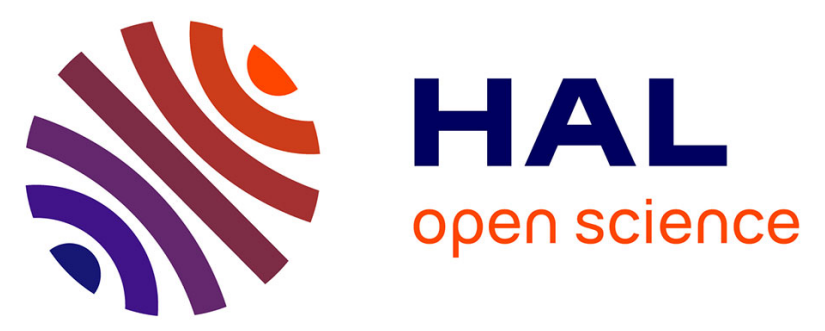

\title{
On the Dual Role of the Reactant during Aqueous Phase Hydrodechlorination of Trichloroethylene (HDC of TCE) using Pd supported on Swellable Organically Modified Silica (SOMS)
}

Saurabh Ailawar, Anagha Hunoor, Benjamin Rudzinski, Laurence Burel, Jean-Marc Millet, Jeffrey T Miller, Paul L Edmiston, Umit S Ozkan

\section{To cite this version:}

Saurabh Ailawar, Anagha Hunoor, Benjamin Rudzinski, Laurence Burel, Jean-Marc Millet, et al.. On the Dual Role of the Reactant during Aqueous Phase Hydrodechlorination of Trichloroethylene (HDC of TCE) using Pd supported on Swellable Organically Modified Silica (SOMS). Applied Catalysis B: Environmental, 2021. hal-03411183

\author{
HAL Id: hal-03411183 \\ https://hal.science/hal-03411183
}

Submitted on 2 Nov 2021

HAL is a multi-disciplinary open access archive for the deposit and dissemination of scientific research documents, whether they are published or not. The documents may come from teaching and research institutions in France or abroad, or from public or private research centers.
L'archive ouverte pluridisciplinaire HAL, est destinée au dépôt et à la diffusion de documents scientifiques de niveau recherche, publiés ou non, émanant des établissements d'enseignement et de recherche français ou étrangers, des laboratoires publics ou privés. 


\section{On the Dual Role of the Reactant during Aqueous Phase Hydrodechlorination of Trichloroethylene (HDC of TCE) using Pd supported on Swellable Organically Modified Silica (SOMS)}

Saurabh Ailawar ${ }^{1}$, Anagha Hunoor ${ }^{1}$, Benjamin Rudzinski ${ }^{1}$, Gokhan Celik ${ }^{1,5}$, Laurence Burel ${ }^{2}$, Jean-Marc Millet ${ }^{2}$, Jeffrey T. Miller ${ }^{3}$, Paul L. Edmiston ${ }^{4}$, Umit S. Ozkan ${ }^{1 *}$

${ }^{1}$ William G. Lowrie Department of Chemical and Biomolecular Engineering, The Ohio State University, 151 W. Woodruff Avenue, Columbus, OH 43210, USA

${ }^{2}$ Univ Lyon, Université Claude Bernard Lyon 1, CNRS, IRCELYON, F-69626, Villeurbanne, France

${ }^{3}$ Davidson School of Chemical Engineering, Purdue University, 480 Stadium Mall Drive, West Lafayette, IN 47907-2100, USA

${ }^{4}$ Department of Chemistry, The College of Wooster, 943 College Mall, Wooster, OH 44691, USA

5Present address:

Department of Chemical Engineering, Middle East

Technical University, Ankara, 06800, Turkey

* Corresponding Author

Prof. Dr. Umit S. Ozkan

E-mail: ozkan.1@osu.edu

Tel: (614)-292-6623 


\begin{abstract}
In this study, dual role of trichloroethylene (TCE) in liquid phase hydrodechlorination reaction performed with Pd supported on swellable organically modified silica (SOMS) is investigated. SOMS is an animated material that swells to 3-4 times its original volume when contacted with organic solvents. Batch-mode activity results of TCE-soaked and dry Pd/SOMS show 45\% higher conversion at the end of $4 \mathrm{~h}$ showing TCE can act as a reactant as well as a swelling agent for SOMS. Additionally, flow reaction experiments and characterization using extended X-ray absorption fine edge structure (EXAFS) helped in investigating this phenomenon further. Liquidphase flow experiments also showed that, reduced Pd species may not be a pre-requisite as reduction can occur, in-situ, by $\mathrm{H}_{2}$ dissolved in water. Time-resolved X-ray absorption near edge spectroscopy (XANES) was performed to observe the in-situ reduction of Pd acetate supported on SOMS by $\mathrm{H}_{2}$ dissolved in water under ambient conditions.
\end{abstract}

Keywords: Pd supported on swellable organically modified silica (SOMS); Hydrodechlorination; Catalyst deactivation; Trichloroethylene; In-situ X-ray absorption near edge spectroscopy (XANES); Hydrophobicity. 


\section{Introduction}

Polychlorinated ethylenes is an important class of organic contaminants; among which, trichloroethylene (TCE) is most commonly found in groundwater with very low solubility (1200 ppm at room temperature) $[1,2]$. The maximum allowable concentration limit of TCE in drinking water is $5 \mathrm{ppb}$ and it is listed as a priority contaminant by US. E.P.A. [3]. Pd catalyzed hydrodechlorination of trichloroethylene (HDC of TCE) is commonly studied owing to its high activity for the cleavage of $\mathrm{C}-\mathrm{Cl}$ bonds present on chlorinated alkanes, chlorinated alkenes and chlorinated aromatics [4-22]. Also, several studies have explored the use of dissolved molecular $\mathrm{H}_{2}$ or organically sourced $\mathrm{H}_{2}$ for HDC of TCE [11, 14-22]. Both gas-phase and aqueous-phase reaction studies have been performed to investigate the role of $\mathrm{Pd}$ supported on $\mathrm{Al}_{2} \mathrm{O}_{3}$ in hydrodehalogenation reactions [23-25]. Furthermore, in an effort to prevent catalyst deactivation and enhance the catalyst activity, various bimetallic configurations such as, $\mathrm{Pd}-\mathrm{Au}, \mathrm{Pd}-\mathrm{Fe}$ and $\mathrm{Pd}-\mathrm{Cu}$ have also been used in the recent years for HDC of TCE. [26-31]. Besides $\mathrm{Al}_{2} \mathrm{O}_{3}$, in recent years, Pd supported on microporous and hierarchical zeolites, carbonaceous supports, $\mathrm{CeO}_{2}, \mathrm{MCM}-41$ have also been investigated $[16,17,32,33]$. These studies have mainly focused on the textural and chemical properties of the support material and the role they play in $\mathrm{Pd}$ distribution and deactivation. However, studies utilizing an animated support have been rarely performed. To that end, our group has recently reported the catalytic performance of $\mathrm{Pd}$ supported on swellable organically modified silica (SOMS) in gas-phase and liquid-phase HDC of TCE [34-39].

SOMS is an animated material which belongs to the class of bridged polysilsesquioxanes [4042]. It is hydrophobic, mesoporous and swells to 4 times its original volume in the presence of organic solvents [40-42]. SOMS is synthesized using a sol-gel method wherein the gel is formed 
by tetrabutylammonium fluoride(TBAF)-catalyzed hydrolytic condensation of bis(trimethoxysilylethyl)benzene (BTEB). After gel ageing and syneresis, the residual silanol groups are derivatized using hexamethyldisilazane (HMDS) to impart hydrophobicity and prevent excessive crosslinking [40-43]. Along with hydrophobicity, high surface area and porosity make SOMS highly absorptive towards organic compounds [42]. Besides being used a catalyst support, application of SOMS as a sorbent for organic contaminants present in wastewater has been demonstrated [40, 44].

The studies performed by our group (HDC of TCE) focus on investigating the potential of SOMS for serving as a better catalyst scaffold than $\mathrm{Al}_{2} \mathrm{O}_{3}$ [34-39]. Liquid phase batch experiments showed that Pd/SOMS, in its completely swollen state, yielded higher conversion of TCE (0.95) than $\mathrm{Pd} / \mathrm{Al}_{2} \mathrm{O}_{3}(0.8)$ for identical operating conditions [38]. Furthermore, $\mathrm{Pd} / \mathrm{SOMS}$ treated with aqueous solutions containing chloride and sulfate anions exhibited better deactivation resistance than $\mathrm{Pd} / \mathrm{Al}_{2} \mathrm{O}_{3}[36,37]$. In particular, experiments involving soaking in $\mathrm{HCl}$ solutions revealed that negligible $\mathrm{Pd}$ was leached out from $\mathrm{Pd} / \mathrm{SOMS}$ as compared to $\mathrm{Pd} / \mathrm{Al}_{2} \mathrm{O}_{3}$. This resistance to leaching, displayed by $\mathrm{Pd} / \mathrm{SOMS}$, was attributed to its hydrophobicity which allows in repelling the $\mathrm{HCl}$ molecules away from $\mathrm{Pd}$ particles [36]. In case of gas-phase studies, $\mathrm{Pd} / \mathrm{SOMS}$ was found to resist deactivation by $\mathrm{H}_{2} \mathrm{O}$ that was added to the feed stream, whereas $\mathrm{Pd} / \mathrm{Al}_{2} \mathrm{O}_{3}$ showed a marked loss in activity [35].

Recently, we also discussed the influence of ethanol (used as a swelling agent) on kinetics and mechanism of HDC of TCE through swelling of SOMS [45]. It was found that ethanol-induced swelling of SOMS allows faster removal of $\mathrm{HCl}$ from the pores causing a decrease in reaction inhibition. Moreover, the reaction was found to be pseudo first order in TCE after the addition of ethanol. 
Our studies have often focused on the use of ethanol as a swelling agent for SOMS. However, in the present study, the role of TCE as a swelling agent (and as a reactant) during HDC reaction is investigated. Experiments performed in both batch and flow reactor set-ups are used to assess the effect of swelling induced by TCE on the catalytic performance. Comparisons with ethanol containing experiments have been drawn to aid in determining the extent of swelling obtained by TCE. Overall, in this study, we aim to determine whether an external swelling agent (such as ethanol) is truly required during HDC of TCE using Pd/SOMS. Activity results, which showed that almost identical steady-state activity could be obtained while starting with either an unreduced or a pre-reduced catalyst are significant since they signal that the requirement of the latter can be eliminated.

\section{Experimental}

\subsection{Catalyst synthesis}

Synthesis of SOMS was previously reported by Edmiston and co-workers [41, 42]. Briefly, SOMS is synthesized using sol-gel method with $0.52 \mathrm{M}$ (BTEB) in tetrahydrofuran as the precursor, followed by addition of water (at a fixed mole ratio 3:1 $\mathrm{H}_{2} \mathrm{O}: \mathrm{BTEB}$ ) and 5.1mM tetrabutylammonium fluoride as the catalyst. After gelation and ageing, the material is washed with acetonitrile followed by derivatization of the surface silanol groups with hexamethyldisilazane (HMDS). The gel is then rinsed with acetone and dried at room temperature followed by grinding in a ball mill at $200 \mathrm{rpm}$. The ground particles were sieved to obtain a particle size of $<74 \mu \mathrm{m}$.

Pd/SOMS was synthesized using incipient wetness impregnation (IWI) technique wherein, a solution with desired concentration (0.059 M for $1 \% \mathrm{Pd}$ loading) of Pd(II) acetate (SigmaAldrich, 99.9\%) in acetone was added dropwise to a thin layer of ground SOMS particles. Visual 
swelling of SOMS particles was noted upon addition of the precursor solution. Intermittent drying of the support was carried out to remove excess acetone, at room temperature. After the entire solution was taken up by the support, it was dried overnight at room temperature. This catalyst was called unreduced $\mathrm{Pd} / \mathrm{SOMS}$ in this study. For reduction, a known quantity of (0.09M for $1 \% \mathrm{Pd}$ loading) $\mathrm{NaBH}_{4}$ was dissolved in $95 \%(\mathrm{v} / \mathrm{v})$ ethanol-water solution. The quantity of $\mathrm{NaBH}_{4}$ was decided to be in excess to ensure complete reduction of Pd acetate. This solution was slowly added to the unreduced Pd/SOMS and a visual color change from pale orange to black was observed. Post reduction, the catalyst was filtered and washed several times with ethanol to get rid of residual impurities. The catalyst was dried at $60^{\circ} \mathrm{C}$, overnight prior to use.

\subsection{Activity testing}

Activity experiments were performed in batch reactor as well as a packed bed reactor.

\subsubsection{Batch reaction experiments}

Batch reactions were performed at $30^{\circ} \mathrm{C}$ and 50 bar, using a $300 \mathrm{~mL} 4560$ mini-benchtop stirred reactor from Parr Instruments Company. The reactor was equipped with 4848-controller for temperature and stirring speed with a PID program. Two-hundred $\mathrm{mL}$ feed solution consisting of known concentration of TCE and tetrahydrofuran (THF) dissolved in water was added to the reactor vessel. THF was used as an internal standard. Once the reactor was sealed, the solution was bubbled with pure $\mathrm{He}$ in order to remove gaseous impurities present in the head-space as well as dissolved in the solution. The impellor speed was set to $2000 \mathrm{rpm}$ and the temperature was stabilized at $30^{\circ} \mathrm{C}$. The impellor speed was optimized such that external mass transfer limitations were not present. The reactor was pressurized in two steps. Initially, 45 bar of pure $\mathrm{H}_{2}$ 
was introduced into the reactor and a sample was drawn out from the liquid phase to obtain the initial concentration of TCE (time=zero sample). As soon as the initial sample was collected, the total pressure of the reactor was raised to 50 bar by introducing $\mathrm{H}_{2}$ through a customized catalyst addition device (CAD) and the reaction was started. CAD is an internal Teflon-sealed chamber holding $5 \mathrm{mg}$ of powdered catalyst. As the reaction progressed, liquid phase samples were collected at intervals of $40 \mathrm{~min}$. In this study, this method is referred to as 'dry catalyst introduction to TCE-containing feed'.

Another set of experiments were performed where the reactor was pressurized in one-step. In this case, use of CAD was bypassed and the catalyst was contacted with TCE for $2 \mathrm{~h}$, in the presence of He. After the temperature was stabilized at $30{ }^{\circ} \mathrm{C}$, the reactor was pressurized to 50 bar of $\mathrm{H}_{2}$. The reactor was operated at 50 bar to maintain the concentration of $\mathrm{H}_{2}$ in excess. Samples were collected at intervals of $40 \mathrm{~min}$ and this method is referred to as 'catalyst pre-contacted with TCE-containing feed solution'.

Organic chlorinated educts were analyzed using high-performance liquid chromatography (HPLC). The samples were shaken and equilibrated prior to injecting into the six-port valve of the solvent delivery module which consisted of acetonitrile and water (Sigma-Aldrich, HPLC grade) as solvents. These solvents were pumped in a gradient mode starting with a 95:5 ratio (acetonitrile:water) proceeding to 50:50, at the end. A C18 column (Grace Alltima), operated under reverse phase, was used for separation of compounds. Lastly, a UV-Vis detector (Shimadzu, SPD-20A) with a deuterium lamp and a dual-channel mode (200/220 nm) was used to detect the compounds.

\subsubsection{Flow reaction experiments}


Packed bed reactions were performed in a home-made reactor system. The packed bed assembly consisted of a gas sparger which was used to bubble $\mathrm{H}_{2}$ through de-ionized (DI) water. $\mathrm{H}_{2}$ bubbling also ensured removal of dissolved gaseous impurities from the DI water. $\mathrm{The}^{-} \mathrm{H}_{2^{-}}$ saturated DI water stream was sent to the reactor at $1 \mathrm{~mL} / \mathrm{min}$ using an ISCO Teledyne 260D syringe pump. A solution of $5000 \mathrm{ppm}$ of TCE dissolved in methanol was added at a rate of 0.25 $\mathrm{mL} / \mathrm{h}$ to the $\mathrm{H}_{2}$ saturated water using an NE-1000 Single Programmable syringe pump. The combined streams were stabilized while bypassing the reactor for $30 \mathrm{~min}$. The reactor was made up of a $0.25^{\prime}$ quartz tube with a constriction that supported $30 \mathrm{mg}$ of catalyst powder immobilized using two quartz-wool plugs. The exit stream was sent to a flow cell connected to a conductivity monitor (Pharmacia Biotech) to measure the concentration of $\mathrm{HCl}$ produced during HDC of TCE. The concentration of $\mathrm{HCl}$ evolved during the reaction served as a measure of catalytic activity which was previously reported by Sohn et al. [35]. The temperature and pressure were maintained at ambient conditions.

\subsection{TCE Equilibrium Adsorption Measurements}

Adsorption of TCE was measured by adding $100 \mathrm{mg}$ of SOMS to $24 \mathrm{~mL}$ of $1,200 \mathrm{mg} / \mathrm{L}$ TCE solution in a sealed vial and shaking the mixture for $3 \mathrm{~h}$. After equilibration, the solutions were filtered with $0.45 \mu \mathrm{m}$ PTFE syringe filters to remove adsorbent and then sealed zero headspace vials. Concentration of TCE was measured by gas chromatography mass spectrometry (GC-MS) using direct aqueous injection [46]. A $10 \mathrm{~m} \times 0.53 \mathrm{~mm}$ HydroGuard ${ }^{\circledR}$ column in series with a Restek $60 \mathrm{~m} \times 0.32 \mathrm{~mm} \times 1 \mu \mathrm{m}$ Stabilwax ${ }^{\circledR}$ column installed in Agilent 6890/5973 GC-MS was used for all direct injection measurements. Selected ion monitoring at $95,132 \mathrm{~m} / \mathrm{z}$ was performed. Calibration curves were run using standards diluted in Type I water. The amount of TCE adsorbed was determine by the depletion of analyte from the solution compared to untreated 
solution. Experiments were repeated 5 times. Adsorption of TCE was evaluated by SOMS in the dry (unswollen) state and after being pre-equilibrated with $20 \%$ or $100 \%$ ethanol. SOMS was pre-equilibrated with $20 \% \mathrm{v} / \mathrm{v}$ ethanol in water for $24 \mathrm{~h}$ removed by filtration, and then added to TCE solution. SOMS becomes fully swollen $(\sim 6 \mathrm{~mL} / \mathrm{g})$ upon addition of $100 \%$ ethanol. Dry SOMS was added to a $24 \mathrm{~mL}$ vial and a minimal amount of ethanol was applied dropwise until full swelling was observed by the appearance of free liquid. Aqueous TCE solution (24mL)was then applied to the ethanol swollen SOMS.

\subsection{Ethanol Adsorption Isotherm}

Dry SOMS (20 mg) was added to $2 \mathrm{~mL}$ of aqueous ethanol solutions and shaken for $8 \mathrm{~h}$ to reach equilibrium. Solutions were then filtered with $0.45 \mu \mathrm{m}$ PTFE syringe filters and ethanol concentration $\left(C_{\mathrm{e}}\right)$ measured by direct injection GC-MS using the selected ion monitoring using $45 \mathrm{~m} / \mathrm{z}$ ion. The same combination of HydroGuard ${ }^{\circledR} /$ Stabilwax $^{\circledR}$ columns were used for all direct injection measurements. Detection was done with an Agilent 5973 MS using selective ion monitoring using the $45 \mathrm{~m} / \mathrm{z}$ ion.. Calibration curves were run using ethanol standards diluted in Type I water. Amount of ethanol adsorbed was determined by depletion compared to untreated

controls and used to determine the mass loading $\mathrm{q}_{\mathrm{e}}$ ( $\left.\mathrm{g}_{\text {ethanol }} / \mathrm{g}_{\mathrm{SOMS}}\right)$. Initial concentrations of ethanol $\left(C_{0}\right)$ ranged from $0.05-0.1 \mathrm{~g} / \mathrm{mL}$. Experiments were run three times for reproducibility.

\subsection{Transmission electron microscopy (TEM)}

TEM images were obtained on a Jeol $2010 \mathrm{LaB}_{6}$ microscope operating at $200 \mathrm{kV}$. The samples were prepared by mixing the catalyst powder with ethanol followed by dispersing this slurry on standard holey carbon-covered copper TEM grids. The particle size distribution analysis was made using FIJI, an open-source platform for biological-image analysis [47]. 


\section{6. $N_{2}$ physisorption}

$\mathrm{N}_{2}$ physisorption was used to determine the textural properties of the catalysts with an accelerated surface area and porosimetry instrument (ASAP 2020) by Micromeritics. A known amount of catalyst was degassed overnight at $120^{\circ} \mathrm{C}$. After degassing was complete, $\mathrm{N}_{2}$ was dosed on the sample while maintaining it at $-196^{\circ} \mathrm{C}$. Once saturate was reached, the material was degassed again to remove the physisorbed $\mathrm{N}_{2}$. The surface area was determined using BrunauerEmmett-Teller (BET) method within the range 0.06-0.2 of the relative pressure [48]. The desorption branch of the isotherm was used to obtain the pore size distribution and pore volume by Barrett-Joyner-Halenda (BJH) method [49]. These experiments were performed for bare and impregnated supports.

\subsection{In-situ X-ray absorption near edge structure (XANES) spectroscopy}

In-situ XANES spectroscopy was performed to investigate the change in oxidation state of Pd in Pd (II) acetate supported on SOMS, as a result of reduction by $\mathrm{H}_{2}$ dissolved in water at room temperature. The experimental set-up is described elsewhere [38, 50, 51]. Briefly, the set up consisted of the flow reactor made up of NMR tubes fused at both ends with $0.25^{\prime}$ quartz tubes with an OD of 0.197' and an ID of 0.167'. The absorption of X-rays (edge-jump) at Pd K-edge $(24350 \mathrm{eV}$ ) was found to be 0.25 and 3.2 , due to reactor material and the catalyst, respectively. An ISCO Teledyne 260D syringe pump was used to flow $\mathrm{H}_{2}$ saturated aqueous solution at a flow rate of $1 \mathrm{~mL} / \mathrm{min}$ over $30 \mathrm{mg}$ of powdered unreduced catalyst packed between two quartz plugs. The data was collected in quick-scan mode (at an interval of about $3 \mathrm{~min}$ ), at the insertion device beamline of the Materials Research Collaborative Access Team (MRCAT-10ID) at Advanced Photon Source, Argonne National Laboratory [52]. A cryogenically cooled double-crystal Si(111) monochromator with a Pt-coated mirror was used. Multiple scans were obtained at the 
start of the experiment to ensure data-reproducibility and each spectrum was accompanied with a Pd foil spectrum used to calibrate the energy at every time-step. The edge energy was determined using first derivative of the absorbance vs energy plot. For data analysis, Athena software was used.

\subsection{Ex-situ soaking in $\mathrm{HCl}$ containing solution}

Pristine $\mathrm{Pd} / \mathrm{SOMS}$ was soaked in aqueous solution of $\mathrm{HCl}$ and TCE to investigate the interaction of $\mathrm{HCl}$ with the catalyst under reaction medium. $\mathrm{No}_{2}$ was used to avoid the occurrence of HDC reaction during soaking experiments. A catalyst amount of $0.35 \mathrm{~g}$ was stirred in a $400 \mathrm{~mL}$ aqueous solution of $0.2 \mathrm{M} \mathrm{HCl}$ and $1000 \mathrm{mg} / \mathrm{L}$ of TCE, in a 0.51 three-necked flask. Prior to adding the catalyst, the flask was flushed with inert gas to remove air. The soaking experiments were performed at ambient pressure and room temperature. The concentration of $\mathrm{HCl}$ was chosen based on the total $\mathrm{HCl}$ concentration produced during the $\mathrm{HDC}$ reaction conducted in batch reactor if complete conversion of TCE was obtained. After soaking, the slurry was filtered, and the catalyst was washed with D.I. water to remove excess anions left on the catalyst. The filtered solid was dried overnight at $110^{\circ} \mathrm{C}$. The same experiment was repeated with a solution of $0.2 \mathrm{M} \mathrm{HCl}$ and $1000 \mathrm{mg} / \mathrm{L}$ of TCE containing $10 \%$ ethanol. All other parameters were maintained the same.

\subsection{Extended X-ray Absorption Fine Edge Structure (EXAFS)}

EXAFS experiments were performed at the bending magnet beamline of the Materials and Research Collaborative Access Team (MRCAT), sector 10 of the Advanced Photon Source, Argonne National Laboratory [53]. Data collection was performed in transmission mode with powder samples pressed into pellets which were supported in a holder consisting of six cylindrical holes. A hole-width of $0.12 \mathrm{~cm}^{2}$ with an optimal catalyst amount was used to obtain a 
maximum edge step $(\Delta \mu x)$ of 0.5 for the $1 \% \mathrm{Pd} / \mathrm{SOMS}$ samples while that obtained for the $\mathrm{Pd}$ foil was about 1.6. Each sample spectrum was accompanied by the foil spectrum that helped in energy calibration. Data analysis was performed using WINXAS97 software following the standard procedure [54]. First derivative spectra were used to determine the threshold energy of the calibrated samples. Least square fits in R-space and k-space of the isolated nearest neighbor were used to determine EXAFS parameters such as the coordination number $(\mathrm{CN})$ and interatomic bond distance $(\mathrm{R})$. References such as $\mathrm{Pd}(\mathrm{II})$ chloride and $\mathrm{Pd}$ foil were used for obtaining phase shifts and backscattering amplitudes. For fitting purpose, $\mathrm{CN}$ and $\mathrm{R}$ associated with $\mathrm{Pd}-\mathrm{Cl}$ scattering in $\mathrm{Pd}(\mathrm{II})$ chloride was 4 and $2.31 \AA$, respectively whereas, with $\mathrm{Pd}-\mathrm{Pd}$ scattering in foil were fixed at 12 and $2.75 \AA$, respectively.

\section{Results and discussion}

\subsection{Transmission electron microscopy (TEM) and $N_{2}$ physisorption}

Catalysts with different metal loading of Pd were synthesized, which resulted in different particle size distribution (PSD), as shown in Figure 1. The PSD was obtained using TEM and the corresponding images are shown in Figure 2. It can be seen that $0.5 \%$ and $1 \% \mathrm{Pd} / \mathrm{SOMS}$ have similar PSDs, whereas that of $1.5 \%$ is shifted towards larger values. Moreover, the PSD of $1.5 \%$ $\mathrm{Pd} / \mathrm{SOMS}$ is broader than that of $0.5 \%$ and $1 \% \mathrm{Pd} / \mathrm{SOMS}$. This indicates that $\mathrm{Pd}$ particles have similar dispersion on $0.5 \%$ and $1 \% \mathrm{Pd} / \mathrm{SOMS}$, however the dispersion is poor on $1.5 \%$ $\mathrm{Pd} / \mathrm{SOMS}$. TEM images with higher resolution comparing the particle size of $0.5 \% \mathrm{Pd} / \mathrm{SOMS}$ and $1 \% \mathrm{Pd} / \mathrm{SOMS}$ are shown in Figure S1. In each case, over 400 particles were counted, and the 
mean particle sizes obtained were $10,10.5$ and $18.6 \mathrm{~nm}$ for $0.5 \%, 1 \%$ and $1.5 \%$ metal loading, respectively.

The changes occurring in the textural properties of SOMS after impregnation of Pd particles were investigated using $\mathrm{N}_{2}$ physisorption and the results are shown in Table 1 . It can be seen that metal incorporation decreased the BET surface area, pore size and pore volume of the pristine support. $\mathrm{N}_{2}$ adsorption-desorption isotherms shown in Fig. 3a and Fig. S2a belong to type IV (as per IUPAC nomenclature) indicating the presence of mesoporosity [55]. Specifically, the hysteresis type belonging to SOMS isotherm can be classified at H2(b) whereas, that belonging to the Pd incorporated samples can be classified at H5 type [56]. The difference in the shapes of bare and Pd-impregnated supports mainly arises due to the presence of a shoulder in the desorption branch of the latter ones (around a relative pressure of $0.45-0.5$ ). H2(b) type isotherm indicates presence of disordered pore network whereas, H5 type indicates presence of partially blocked or narrow pores [55]. Both isotherms exhibit a forced loop closure at relative pressure of 0.42 , in their desorption branch. This behavior is caused due to tensile strength effect present during $\mathrm{N}_{2}$ desorption [57]. Moreover, the presence of these effects in $\mathrm{N}_{2}$ physisorption isotherms further show up in the BJH pore size distribution (PSD) at $3.7 \mathrm{~nm}$. This means that features observed at $3.7 \mathrm{~nm}$ in the PSD are merely artifacts of cavitation-controlled desorption of metastable $\mathrm{N}_{2}$ (instead of presence of actual pores) [57].

On comparing the PSD shown in Fig. $3 b$ and Fig. S2b, the population of the larger pores in bare support appeared to have vanished after Pd impregnation, indicating that Pd particles may have occupied these pores. This is consistent with the above mentioned fact that H5 type hysteresis loop shown by Pd impregnated samples indicate narrow pore neck widths. Finally, PSD of Pd impregnated catalysts show the presence of pores of similar size in all catalysts. However, the 
average pore-size obtained after Pd impregnation for all catalysts, is smaller than the average size of Pd particles (obtained by TEM) in these samples. In order to reconcile this fact, swelling and shrinking phenomenon of SOMS must be taken into consideration. During impregnation of these particles, SOMS is in its swollen state which allows the particles to be deposited deep inside the pores; however, SOMS is in its shrunken state during $\mathrm{N}_{2}$ physisorption, and hence, the observed textural properties may not be fully representative of the properties under its swollen conditions. Therefore, swelling obtained during synthesis can enable Pd particles, as large as $18.6 \mathrm{~nm}$, to be situated inside the pores of SOMS.

Thus, SOMS can uptake these large particles inside its pores, despite a smaller pore size observed $\mathrm{N}_{2}$ physisorption. Besides, TEM is a bulk technique which can show particles that may not be accessible to $\mathrm{N}_{2}$ during $\mathrm{N}_{2}$ physisorption. An evidence of this possibility was provided in our recent work, where heat-treatment of SOMS at $400{ }^{\circ} \mathrm{C}$, led to an increase in the pore-size from $3.7 \mathrm{~nm}$ to almost $13 \mathrm{~nm}$ [56]. A significant increase in surface area and pore volume was observed after heat treatment. This shows that the flexible nature of the support can allow the accommodation of much larger Pd particles which cannot be directly correlated to its present textural properties.

\subsection{Effect of metal loading on HDC of TCE in batch reactor}

Considering that PSD and the mean particle sizes of $0.5 \%$ and $1 \% \mathrm{Pd} / \mathrm{SOMS}$ were similar, activity tests were performed on these catalysts to circumvent the effects caused by metal particle size. Figure 4a compares the catalytic performance for HDC of TCE with different metal loadings in the presence and absence of ethanol. It can be seen that in both cases, the rate increases with metal loading. However, as the reaction proceeds, the rate of conversion of TCE 
slows down for both catalysts in absence of ethanol. At the end of $240 \mathrm{~min}, 30 \%$ conversion is obtained using $0.5 \% \mathrm{Pd} / \mathrm{SOMS}$ whereas, $51 \%$ conversion is obtained using $1 \% \mathrm{Pd} / \mathrm{SOMS}$. The extent of $\mathrm{HCl}$ inhibition depends on the metal loading and conversion of TCE, such that, catalyst with higher metal loading is deactivated at higher conversion of TCE. The extent of conversion of TCE determines the concentration of $\mathrm{HCl}$ produced and hence, dictates the extent of inhibition.

In the presence of ethanol, negligible deactivation was observed. This was confirmed by fitting the data to a kinetic model, first order in TCE as shown in Figure 4b. The first order model was chosen based on the mechanism proposed recently (also shown in SI) [45]. This indicates that ethanol allows faster removal of $\mathrm{HCl}$ from the pores such that even the catalyst with lower metal loading was found to sustain its activity. As per the rate expression provided in the SI [45], the apparent rate constant obtained from fitting, should be directly proportional to the total amount of metal sites for catalysts with similar dispersion and/or particle size. The ratio of the apparent rate constants for $0.5 \%$ and $1 \% \mathrm{Pd} / \mathrm{SOMS}$ was found to be 1.9 , which is almost equivalent to the ratio of their metal content.

According to the criterion proposed by Madon-Boudart for liquid phase reactions, the turnover frequency of a reaction is independent of the metal loading of the catalyst in absence of mass transfer limitations [58]. In other words, if catalysts with different metal loadings and similar dispersion were synthesized, the rate must be proportional to the metal loading. Furthermore, for liquid phase hydrogenation using a $\mathrm{Pt} / \mathrm{SiO}_{2}$ catalyst, Singh et al. demonstrated that the accessibility of the active sites can be tested simply with two catalysts with different metal loadings but similar dispersion [59]. Our results satisfy the Madon-Boudart criterion suggesting that all metal sites are accessible in the presence of $10 \%$ ethanol. 


\subsection{Sorption of TCE and ethanol in SOMS}

Equilibrium adsorption of TCE and ethanol in SOMS was used to determine their partition coefficients which are defined as ratio of moles of TCE bound to SOMS per mg of SOMS to concentration of TCE in the solution [40]. Partition coefficient of ethanol with respect to SOMS from an aqueous solution was found to be 55, as obtained from the ethanol adsorption isotherm shown in Figure 5. This value is significantly lower than that of TCE which was found to be 5500. This indicates that polarity of organic solvent plays an important role in determining its sorption in SOMS. This phenomenon is further elaborated on in the study conducted by Edmiston et al., where partition coefficients of several other organics were determined [40]. Similarly, Celik et al., compared the sorption of acetone and water on both SOMS and Pd/SOMS and confirmed that acetone being less polar than water, its sorption is favored on SOMS over that of water [38]. This also shows that even if the sorbate is polar, its organic nature allows its entry inside SOMS.

Partition coefficient of TCE in SOMS was also determined after pre-treatment with varied concentrations of ethanol $(0 \%, 20 \%$ and $100 \%$ ethanol) as shown in Table S1. It was found that an increase in concentration of ethanol pre-treatment led to a decrease in the partition coefficient of TCE in SOMS. This trend is consistent with that observed from the theoretical calculations reported in the our previous study [45]. Since swelling would afford larger pore size and pore volume, the sorption of TCE would be expected to be higher for swollen SOMS (compared to unswollen state). However, that is not the case because, in the presence of ethanol, competitive binding will lead to the pores being partially occupied by ethanol molecules, resulting in a decrease in the pore volume/adsorption sites available for sorption of TCE. Thus, at higher pre- 
treatment concentrations of ethanol, lower apparent sorption affinity of TCE was observed. Furthermore, addition of ethanol to water-TCE mixture increased the solubility of TCE in that mixture, resulting in a decrease in its partition coefficient in SOMS [45]. This leads to a lower TCE sorption, even when SOMS is swollen by ethanol. A possible benefit of organic absorption capacity of SOMS can be to trap ethanol as it is released from the catalyst in order to remove it from the water. This is because, the ethanol added to the reaction media for swelling of $\mathrm{Pd} / \mathrm{SOMS}$, needs to be separated from the water. However, another strategy which can be used to bypass the use of ethanol for obtaining swelling of Pd/SOMS during reaction, is discussed in the upcoming sections.

\subsection{Effect of pre-contacting with TCE on the catalytic performance of Pd/SOMS (batch reactor)}

Catalytic performance of a material such as $\mathrm{Pd} / \mathrm{SOMS}$ is dependent on the extent of swelling as noted in studies performed with animated support materials [60, 61]. In our case, absorptioninduced swelling can be achieved only by organics due to hydrophobicity of SOMS [40, 41]. As discussed in the previous section, polarity and concentration of the dissolved organic solute collectively determines its extent of absorption into SOMS thereby governing the extent of swelling $[40,42]$. This implies that a constant supply of organics can saturate SOMS thereby allowing complete swelling [40, 62]. Therefore, batch experiments were performed to swell $\mathrm{Pd} / \mathrm{SOMS}$ with TCE prior to addition of $\mathrm{H}_{2}$ since the concentration of TCE in the bulk solution can be maintained at a high value in absence of reaction.

The results of pre-contacting the catalyst with TCE solution and those of adding dry catalyst to the TCE and $\mathrm{H}_{2}$ solution are compared in Figure 6a. During the entire reaction, higher 
conversion was obtained when the catalyst was pre-contacted with TCE. Absorption of TCE in SOMS, prior to reaction may result in swelling of the matrix which can allow faster removal of $\mathrm{HCl}$ formed in the reaction. Thus, the catalyst may suffer from little or no inhibition if precontacted with TCE. In order to investigate the extent of deactivation, mole fraction of cisdichloroethylene (cis-DCE), was monitored and is depicted in Figure 6b. The mole fraction of cis-DCE, shown here, is defined as the ratio of moles of cis-DCE to the total moles of chlorinated species present in the system. Our recent study reported that, among the partially dechlorinated intermediates, concentration of cis-DCE was higher than others [38]. Cis-DCE being an intermediate, its occurrence during the course of the reaction is a net result of its formation as well as consumption. The overall trend associated with the occurrence of cis-DCE shows a plateau-type behavior in absence of ethanol. However, in presence of ethanol, no such plateau-type behavior is observed indicating that cis-DCE is eventually consumed in the reaction. After pre-contacting the catalyst with TCE, occurrence of cis-DCE was observed to go through a maximum as opposed to a plateau (Fig. 6b). Thus, following a rationale similar to the ethanol containing case, inhibition due to $\mathrm{HCl}$ may have significantly reduced by pre-contacting the catalyst with TCE. Thus, swelling can be considered to aid in the removal of HCl. To assess the extent of swelling obtained by pre-contacting the catalyst with TCE, effect of metal loading was investigated.

Effect of pre-contacting catalysts containing different metal loadings (1\% and 0.5\%), with TCE is shown in Figure 7a. For both the metal loadings, a significant improvement in the final conversion of TCE is obtained after pre-contacting the catalyst with TCE. The linearized plots of conversion vs time (Fig. 7b) show that, after $40 \mathrm{~min}$, the reaction exhibits pseudo-first order behavior. Initially, there is an abundance of TCE in the vicinity of Pd sites on SOMS and as $\mathrm{H}_{2}$ is 
introduced in the reaction system, TCE is rapidly converted. As the HDC reaction proceeds, the local concentration of TCE decreases significantly relative to that of $\mathrm{H}_{2}$, since $\mathrm{H}_{2}$ is supplied constantly. The reaction can then become pseudo-first order in TCE, with $\mathrm{H}_{2}$ as the most abundant surface species.

Higher pseudo-first order rate constant was obtained for $1 \% \mathrm{Pd} / \mathrm{SOMS}$ than $0.5 \% \mathrm{Pd} / \mathrm{SOMS}$, however the ratio of their rate constants (3.07) is not equivalent to the ratio of their metal loading ( 2). This does not satisfy the Madon-Boudart criterion for accessibility of active sites. However, as mentioned in previous section, even without pre-contacting, presence of $10 \%$ ethanol ensured complete accessibility to active sites by satisfying the Madon-Boudart criterion. This could be due to swelling of SOMS which allows complete accessibility to active sites. The extent of swelling depends on the concentration of swelling agent, as mentioned in section 3.3. The concentration of TCE in the feed mixture $(250 \mathrm{ppm})$ is significantly lower than that of $10 \%$ ethanol (79,000 ppm) which implies swelling induced by adsorption of TCE alone (dissolved in water) can be significantly lower than that obtained by $10 \%$ ethanol. Additionally, the concentration of TCE decreases due to reaction but that of ethanol stays constant. This can explain the low accessibility to active sites obtained by pre-contacting the catalyst with TCE. In order to maintain a constant supply of TCE while performing the HDC reaction, experiments were performed in a flow system as discussed below.

\subsection{Aqueous phase HDC of TCE performed in a flow reactor}

Continuous supply of TCE can maintain Pd/SOMS in swollen state throughout the reaction time. Activity experiments were therefore performed in a flow system under ambient temperature and pressure, with excess $\mathrm{H}_{2}$, where TCE was supplied in a continuous mode. We have recently 
shown that Pd acetate supported on SOMS can be reduced by $\mathrm{H}_{2}$ dissolved in water at room temperature and ambient pressure [38]. Therefore, activity tests were performed starting with an unreduced catalyst.

Figure 8 shows the effect of addition of ethanol to the reaction performed using unreduced and pre-reduced $\mathrm{Pd} / \mathrm{SOMS}$. Pre-reduction was performed at room temperature, using $\mathrm{NaBH}_{4}$ dissolved in $95 \%$ ethanol solution. The measure of activity was determined using $\mathrm{HCl}$ concentration produced in the reaction. Similar steady state $\mathrm{HCl}$ concentration was obtained in presence and absence of $10 \%$ ethanol. However, with addition of $10 \%$ ethanol to a feed containing ppm levels of TCE, the overall concentration of organics is increased to an extent that rapid swelling of Pd/SOMS occurs. This supports the observation that steady-state is reached faster in presence of $10 \%$ ethanol. This indicates that, swelling obtained in either case is similar. Had the catalyst been swollen to lesser extent in absence of $10 \%$ ethanol, less Pd particles would have been accessible, resulting in lower steady state activity. Since that is not the case, it can be said that swelling obtained by TCE is similar to that obtained by $10 \%$ ethanol, thereby removing the mass transfer limitations. Furthermore, swelling by TCE (in absence of ethanol) can be achieved through its absorption into the pores of SOMS. This phenomenon was previously reported by our group wherein, $\mathrm{HCl}$ production was observed for a significantly long time on $\mathrm{Pd} / \mathrm{SOMS}$, even after stopping the supply of TCE (keeping $\mathrm{H}_{2}$ supply $\mathrm{ON}$ ), during an ongoing flow reaction experiment [35]. Thus, $\mathrm{H}_{2}$ molecules that were being supplied, reacted with the TCE absorbed in the catalyst alone. In order to ensure that this reaction was indeed with the absorbed TCE (as opposed to that present in the lines) the same experiment was performed with the commercial $\mathrm{Pd} / \mathrm{Al}_{2} \mathrm{O}_{3}$ catalyst, which showed a rapid drop in $\mathrm{HCl}$ production as soon as the TCE supply was stopped [35]. This, demonstrated the superior absorption capacity of Pd/SOMS 
than $\mathrm{Pd} / \mathrm{Al}_{2} \mathrm{O}_{3}$. This is also consistent with the fact that $\mathrm{Pd} / \mathrm{SOMS}$ has high affinity for organics and has higher porosity than $\mathrm{Pd} / \mathrm{Al}_{2} \mathrm{O}_{3}[38]$.

The effect of ethanol was found to be more prominent for unreduced Pd/SOMS ( $\mathrm{Pd}$ acetate impregnated on SOMS). It can be seen from Figure 8 that, for unreduced catalysts, presence of ethanol not only led to rapid reduction, but it also helped achieve the same steady-state $\mathrm{HCl}$ concentration as that of the reduced catalysts. The performance of unreduced Pd/SOMS in absence of ethanol showed a slow yet increasing production of $\mathrm{HCl}$ with time. This implies that $\mathrm{H}_{2}$ molecules entering the catalyst pores reduce the impregnated $\mathrm{Pd}$ acetate, resulting in the formation of active Pd particles. Subsequently, the incoming TCE molecules can react with rest of the $\mathrm{H}_{2}$ molecules on these active Pd particles, producing $\mathrm{HCl}$. The theoretical demand of $\mathrm{H}_{2}$ required for reduction of $\mathrm{Pd}$ acetate with given operating conditions can be fulfilled in $3.5 \mathrm{~min}$ after starting the reaction; however, this reduction can be slowed because $\mathrm{H}_{2}$ is simultaneously required for the HDC reaction as well. Thus, $\mathrm{H}_{2}$ is being utilized for two processes simultaneously: reduction of Pd acetate and HDC reaction with TCE.

As mentioned previously, excess availability of $\mathrm{H}_{2}$ in the pores is required for suppression of inhibition by $\mathrm{HCl}$; however, as $\mathrm{H}_{2}$ is being shared for $\mathrm{Pd}$ acetate reduction and $\mathrm{HDC}$ reaction, its excess availability for HDC reaction alone cannot be maintained. It is therefore possible that, in absence of ethanol, inhibition due to $\mathrm{HCl}$ may slow down the $\mathrm{HDC}$ reaction until the incoming $\mathrm{H}_{2}$ is entirely available for HDC reaction. This inference is consistent with our explanation provided for the batch reactor studies mentioned previously [45].

A visual observation of the unreduced catalyst bed in absence of ethanol is depicted in Figure 9. It was found that the pale orange color of Pd acetate transformed into black, indicating reduction to form metallic Pd. The reduction phenomenon is further demonstrated in the section 3.6. 
In presence of ethanol, faster access to all active sites for $\mathrm{H}_{2}$ may be caused due to rapid swelling. Furthermore, ethanol may itself act as a reducing agent allowing even faster reduction of $\mathrm{Pd}$ acetate [63]. The assisted reduction by ethanol can allow most of the $\mathrm{H}_{2}$ to participate in the HDC reaction instead of being shared for Pd acetate reduction. Thus, the combined effect of rapid swelling and aided reduction of Pd acetate can result in faster achievement of steady-state. These results show that even without any pre-treatment, Pd/SOMS can be reduced, in-situ, while the reaction occurs.

The effect of ethanol concentration on HDC reaction with unreduced $\mathrm{Pd} / \mathrm{SOMS}$ was also explored and, the results are shown in Figure 10. Steady state was not reached with $0 \%$ and $1 \%$ ethanol case, in the experimental duration of this study. However, when the concentration was increased further, steady-state was achieved. It was observed that for 5\% and $10 \%$ ethanol, the steady-state $\mathrm{HCl}$ concentration was higher than that for $20 \%$. This decrease in activity could be due a significant increase in the solubility of TCE in $20 \%$ ethanol resulting in lower sorption of TCE in SOMS. This is consistent with our findings about the effect of ethanol on the sorption of TCE in SOMS as mentioned in section 3.3.

Lastly, in order to determine whether Pd losses occurred during the flow reaction, an experiment was conducted with $10 \%$ ethanol in the system (Figure S3). This concentration of ethanol was chosen so that all Pd particles in the catalyst can be exposed during reaction, through rapid and complete swelling of SOMS (and if any Pd losses were to occur, they can be easily observed). In this experiment, TCE supply was stopped (while keeping $\mathrm{H}_{2}$ supply on) after 90 min of reaction time and the $\mathrm{HCl}$ was allowed to elute out of the system (Figure S3). After 180 minutes, the supply of TCE was restarted and the $\mathrm{HCl}$ production was monitored. It was found that $\mathrm{HCl}$ production similar to that in cycle 1 was observed, indicating that hardly any Pd losses had 
occurred during the reaction. This is expected because, the hydrophobic pore-structure of SOMS repels $\mathrm{HCl}$ from $\mathrm{Pd}$ thereby shielding it. This stable behavior is consistent with our earlier results, where $\mathrm{Pd} / \mathrm{SOMS}$ was soaked in an aqueous solution containing known concentration of $\mathrm{HCl}$ and the resulting filtrate was analyzed using inductively coupled plasma optical emission spectrometry (ICP-OES) [36]. It was found that less than $1 \%$ of $\mathrm{Pd}$ was leached out of $\mathrm{Pd} / \mathrm{SOMS}$. When the same experiment was repeated with $\mathrm{Pd} / \mathrm{Al}_{2} \mathrm{O}_{3}$, the commercial catalyst, more than $75 \%$ Pd was leached out. Thus, Pd/SOMS was found to be more resistant towards deactivation by $\mathrm{HCl}$. This behavior suggests that $\mathrm{Pd} / \mathrm{SOMS}$ has a high potential to serve as a catalyst for HDC of TCE.

\subsection{Time resolved in-situ $X$-ray absorption near-edge structure (XANES)}

When starting with an unreduced catalyst, its reduction is essential to generate Pd species active for HDC of TCE [11]. The aqueous phase reduction of Pd acetate supported on SOMS, performed with dissolved $\mathrm{H}_{2}$ under ambient conditions, was reported by Celik et al., wherein a comparison was made with $\mathrm{Pd}$ oxide supported on $\mathrm{Al}_{2} \mathrm{O}_{3}$ [38]. The results showed that faster reduction was obtained on $\mathrm{Pd}$ oxide supported on $\mathrm{Al}_{2} \mathrm{O}_{3}$ possibly due to higher accessibility of sites. In this study, in-situ reduction of Pd acetate on SOMS by $\mathrm{H}_{2}$ dissolved in aqueous streams under varied ethanol concentrations, was investigated. The XANES spectra (Pd K-edge: 24320$24370 \mathrm{eV}$ ) shown in the normalized absorbance vs energy plot (Fig. 11) depict the temporal reduction of $\mathrm{Pd}$ in absence and presence of $5 \%$ ethanol. In order to observe the transient reduction profile, $5 \%$ ethanol was chosen as opposed to $10 \%$. In-situ reduction in presence of $1 \%$ ethanol is shown in Figure S4. $\mathrm{Pd}$ foil $\left(\mathrm{Pd}^{0}\right)$ and $\mathrm{Pd}$ acetate $\left(\mathrm{Pd}^{2+}\right)$ were used as references to 
determine the extent of reduction and, the XANES spectra corresponding to these compounds are depicted by dashed lines. The energy thresholds corresponding to $\operatorname{Pd}(0)$ and $\operatorname{Pd}(\mathrm{II})$ were found to be $24350 \mathrm{eV}$ and $24354 \mathrm{eV}$, respectively [64]. As reduction occurred, the spectra shifted towards that of the foil showing formation of $\operatorname{Pd}(0)$ species. Along with the shift in the spectra, changes were also observed in the intensity of white line, which is a feature obtained just after the edge region $[65,66]$. It can be seen that, as time progresses, the white line intensity decreases showing formation of reduced species, which is evident from the fact that intensity of white line for the reference metallic $\mathrm{Pd}$ is lower than $\mathrm{Pd}$ acetate.

The contribution from oxidized and reduced Pd species to the overall oxidation state of Pd was determined using linear combination analysis. The overall oxidation state of Pd particles was then used to obtain conversion of $\mathrm{Pd}^{2+}$ to $\mathrm{Pd}^{0}$. Figure 12 shows the effect of concentration of ethanol on the rate of conversion of $\mathrm{Pd}^{2+}$ sites to $\mathrm{Pd}^{0}$. It can be observed that an increase in the concentration of ethanol from $0 \%$ to $1 \%$ did not affect the rate of $\mathrm{Pd}^{2+}$ conversion significantly. However, faster rate of reduction was obtained with 5\% ethanol. It should be noted that addition of $5 \%$ ethanol to water does not lead to any significant increase in the solubility of $\mathrm{H}_{2}$ [67]. This ensures that the faster reduction in presence of $5 \%$ ethanol is not due to higher concentration of dissolved $\mathrm{H}_{2}$. Therefore, ethanol can be considered to swell the catalyst and increase the accessibility of active sites during reduction.

In literature, ethanol is known to be a reductant itself (forming acetaldehyde) [63], however, insitu characterization pertaining to the liquid phase reduction of supported metal ions under ambient conditions has been rarely reported. Hence, a control experiment was run to assess the reducibility of $5 \%$ ethanol without $\mathrm{H}_{2}$. XANES spectra shown in Figure 11a and $11 \mathrm{~b}$ involve dissolved $\mathrm{H}_{2}$ and ethanol as reductants, however, spectra shown in Figure 11c involve only 5\% 
ethanol (without any $\mathrm{H}_{2}$ ) as the reductant. Figure $12 \mathrm{~b}$ quantitatively compares the reduction of $\mathrm{Pd}^{2+}$ with 5\% ethanol in presence and absence of $\mathrm{H}_{2}$. It can be clearly observed that in the first 6 min, negligible reduction with $5 \%$ ethanol was obtained whereas, with the addition of $\mathrm{H}_{2}$, almost $70 \%$ of the sites were reduced. This demonstrates that the reduction ability of ethanol is much lower than that of $\mathrm{H}_{2}$; however, it is not negligible. It should be noted that all Pd sites were not found to be reduced in either case, however, higher fraction of Pd sites are reduced with $\mathrm{H}_{2}$ dissolved in 5\% ethanol. Thus, fraction of reduced Pd sites is proportional to the concentration of ethanol used. This indicates that, as higher ethanol concentrations are employed, more absorption of ethanol can occur leading to better swelling and higher accessibility to Pd. It is also conceivable that above a certain concentration of ethanol (which allows complete swelling) further Pd reduction may not be observed.

Furthermore, the activity data shown in Figure 8 and Figure 10 indicate that, the steady-state concentration of $\mathrm{HCl}$ obtained in presence of $5 \%$ ethanol starting with an unreduced catalyst, is the same as that without ethanol but a pre-reduced catalyst. This implies that the unreduced catalyst could be completely reduced in presence of 5\% ethanol during HDC reaction. However, in-situ XANES show that $84 \%$ of $\mathrm{Pd}$ is reduced with dissolved $\mathrm{H}_{2}$ in presence of $5 \%$ ethanol (Fig. 12a). One explanation for this difference could be that TCE present during HDC reaction conditions may also aid in swelling SOMS and hence provide more accessibility to $\mathrm{H}_{2}$ for reduction. Hydrophobicity of TCE being higher than ethanol, its partition coefficient and hence absorption in SOMS could be higher. Thus, the swelling induced by TCE can be responsible for reduction of the remaining $\mathrm{Pd}^{2+}$ species that could not be reduced in presence of 5\% ethanol alone. 


\subsection{Extended X-ray Absorption Fine Structure (EXAFS)}

To determine the effect of ethanol in absence of $\mathrm{H}_{2}, \mathrm{Pd} / \mathrm{SOMS}$ samples were soaked in aqueous solution of $0.2 \mathrm{M} \mathrm{HCl}$ and $1000 \mathrm{ppm}$ TCE (in presence and absence of 10\% ethanol). EXAFS spectra were obtained to investigate the atomic environment of Pd after the soaked samples were

dried. Figure 13 shows the Fourier transform (FT) magnitude of $\mathrm{k}^{2}$ weighted chi(k) (not corrected for phase-shift) of three Pd/SOMS catalysts. Spectra belonging to the pristine sample are also shown for comparison. Table 2 shows the coordination numbers $(\mathrm{CN})$ and bond distances (R) obtained after fitting the spectra (Figure 13).

Pd-Pd scattering with a $\mathrm{CN}$ and $\mathrm{R}$ of 8.5 and $2.74 \AA$ respectively, was observed in the pristine samples. When this sample was soaked in solution containing $\mathrm{HCl}$ and TCE, changes occurred in the bulk of $\mathrm{Pd}$ particles giving rise to $\mathrm{Pd}-\mathrm{Cl}$ interactions. This can be seen by the presence of additional features obtained in the $\mathrm{k}^{2}$ weighted FT magnitudes corresponding to $\mathrm{Pd}-\mathrm{Cl}$ bonds [68]. Formation of Pd-Cl bonds (CN: 2.1) was accompanied by a decrease of Pd-Pd CN (CN for pristine: 8.5 and $\mathrm{CN}$ for $\mathrm{HCl}$ and TCE soaked sample: 6.5). In our previous work, it was reported that complete chlorination of $\mathrm{Pd} / \mathrm{Al}_{2} \mathrm{O}_{3}$ was observed with soaking in $0.01 \mathrm{M} \mathrm{HCl}$ whereas, $\mathrm{Pd} / \mathrm{SOMS}$ was found to be unaffected [36]. These results support that in absence of $\mathrm{H}_{2}$, bulk chlorination of $\mathrm{Pd}$ is probable in presence of $\mathrm{HCl}$. However, in this study, even after employing twenty times higher $\mathrm{HCl}$ concentration with the additional presence of TCE, during ex-situ soaking, only partial chlorination of Pd supported on SOMS was observed [36]. It can be said that even in presence of TCE, the externally added $\mathrm{HCl}$ could not access all the active Pd sites, possibly due to its polar nature and less solubility in TCE. Furthermore, hydrophobicity of SOMS could additionally prevent the influx of $\mathrm{HCl}$ in the pores thereby shielding the internally situated Pd particles. 
With addition of ethanol, the decrease in $\mathrm{Pd}-\mathrm{Pd} \mathrm{CN}$ was from 8.5 to 7.2 with a corresponding $\mathrm{Pd}$ $\mathrm{Cl} \mathrm{CN}$ of 1.2. This indicates that, ethanol prevented the bulk chlorination of Pd leading to the presence of more reduced species in the catalyst. This can be attributed to two factors: high surface coverage and reducibility of ethanol. As mentioned previously, ethanol being an organic its absorption into SOMS is preferred over that of water and $\mathrm{HCl}$. However, once inside SOMS, ethanol tends to adsorb on the surface of Pd leading to high surface coverage [45]. This decreases the probability of interaction between $\mathrm{HCl}$ and $\mathrm{Pd}$ which could ultimately result in low Pd chlorination. Moreover, in Section 3.6 (in-situ XANES), it was shown that ethanol itself can act as a reducing agent, suggesting that the oxidative chlorination of $\mathrm{Pd}$ by $\mathrm{HCl}$ could also be prevented by the reductive action of ethanol.

Lastly, these observations support the explanation regarding the effect of ethanol on activity of unreduced Pd/SOMS (Section 3.5). In that case, during the HDC reaction, the incoming $\mathrm{H}_{2}$ molecules could be interacting with the unreduced $\mathrm{Pd}$ species to form reduced $\mathrm{Pd}$ particles. Subsequently, further incoming $\mathrm{H}_{2}$ molecules can react on this newly Pd surface (with TCE) to produce $\mathrm{HCl}$ molecules which may, in turn, inhibit the reaction. However, when ethanol is added to this system, inhibition due to $\mathrm{HCl}$ can be prevented because ethanol facilitates transfer of $\mathrm{HCl}$ out of the catalyst pores and suppresses its adsorption on Pd sites.

\section{Conclusion}

The role of TCE during HDC of TCE was found to be more than just of a reactant. TCE sorption into the pores of SOMS also led to swelling of SOMS which aided in removing $\mathrm{HCl}$ from the pores. This further bolstered the findings that swelling is necessary for faster removal of $\mathrm{HCl}$ 
from pores along with higher $\mathrm{H}_{2}$ concentrations. However, batch data suggested that swelling obtained due to TCE under transient conditions is not reliable as the number of active sites exposed in each case was different. Experiments performed in continuous mode showed that steady state $\mathrm{HCl}$ concentration did not differ with and without addition of ethanol. These results led to the conclusion that TCE itself can swell the catalyst.

Besides being able to swell the catalyst with TCE, another operating condition eased during the flow experiments was the requirement of a pre-reduced catalyst. It was found that in-situ reduction of $\mathrm{Pd}$ acetate could be performed by $\mathrm{H}_{2}$ during the HDC reaction. For an unreduced catalyst, although a slow rise to steady-state was observed in absence of ethanol, the addition of ethanol accelerated the achievement of steady-state. The faster achievement of steady-state was found to be related to swelling and reduction ability of ethanol. In-situ characterization of the reduction of $\mathrm{Pd}$ acetate by $\mathrm{H}_{2}$ revealed that presence of ethanol speeded the reduction process in two ways: (i) ethanol facilitates swelling of SOMS, (ii) ethanol acts as a reductant itself. However, it was found that complete reduction could not be obtained with $5 \%$ ethanol, although, it was enough to yield similar HDC activity as that of the pre-reduced catalyst. This further suggests that, in addition to ethanol, TCE could play a role in swelling SOMS.

\section{Acknowledgements:}

This work was financially supported by the National Science Foundation through the Grant CBET- 1436729 and Ohio Coal Research Consortium. J.T.M. was supported as part of the

National Science Foundation Energy Research Center for Innovative and Strategic Transformation of Alkane Resources (CISTAR) under the Cooperative Agreement No. EEC1647722. EXAFS data was collected at the Materials Research Collaborative Access Team's 
(MRCAT) sector 10- ID-B at Argonne National Laboratory. MRCAT operations are supported by the Department of Energy and the MRCAT member institutions. This research used resources of the Advanced Photon Source, a U.S. Department of Energy (DOE) Office of Science User Facility operated for the DOE Office of Science by Argonne National Laboratory under Contract No. DE-AC02-06CH11357. The authors would like to thank Allison Curtze and Eric Painting for assistance with ethanol adsorption measurements.

\section{References:}

[1] M.J. Moran, Occurrence and implications of selected chlorinated solvents in ground water and source water in the United States and in drinking water in 12 northeast and mid-Atlantic states, 1993-2002, in, 2006.

[2] P.J. Squillace, C.V. Price, Urban land-use study plan for the National Water-Quality Assessment Program, in, US Geological Survey; Branch of Information Services [distributor], 1996.

[3] U. EPA, National primary drinking water regulations, Arsenic and Clarifications to, (2009). [4] C. Thompson, R. Rioux, N. Chen, F. Ribeiro, Turnover rate, reaction order, and elementary steps for the hydrodechlorination of chlorofluorocarbon compounds on palladium catalysts, The Journal of Physical Chemistry B, 104 (2000) 3067-3077.

[5] F. Ribeiro, C. Gerken, G. Somorjai, C. Kellner, G. Coulston, L. Manzer, L. Abrams, Turnover rate and kinetic mechanism for the reaction of hydrodechlorination of 1, 1dichlorotetrafluoroethane (CF 3-CFCl 2) over a polycrystalline Pd foil, Catalysis letters, 45 (1997) 149-153. 
[6] N. Chen, R.M. Rioux, F.H. Ribeiro, Investigation of reaction steps for the hydrodechlorination of chlorine-containing organic compounds on Pd catalysts, Journal of Catalysis, 211 (2002) 192197.

[7] G. Yuan, M.A. Keane, Liquid phase hydrodechlorination of chlorophenols over Pd/C and $\mathrm{Pd} / \mathrm{Al2O}$ : a consideration of $\mathrm{HCl} /$ catalyst interactions and solution $\mathrm{pH}$ effects, Applied Catalysis B: Environmental, 52 (2004) 301-314.

[8] G. Yuan, M.A. Keane, Role of base addition in the liquid-phase hydrodechlorination of 2, 4dichlorophenol over Pd/Al2O3 and Pd/C, Journal of Catalysis, 225 (2004) 510-522.

[9] M.O. Nutt, J.B. Hughes, M.S. Wong, Designing Pd-on-Au Bimetallic Nanoparticle Catalysts for Trichloroethene Hydrodechlorination, Environ Sci Technol, 39 (2005) 8.

[10] G.V. Lowry, M. Reinhard, Pd-Catalyzed TCE Dechlorination in Groundwater: Solute Effects, Biological Control, and Oxidative Catalyst Regeneration, Environmental Science and Technology, 34 (2000) 7.

[11] G.V. Lowry, M. Reinhard, Hydrodehalogenation of 1- to 3-Carbon Halogenated Organic Compounds in Water Using a Palladium Catalyst and Hydrogen Gas, Environ Sci Technol, 33 (1999) 6.

[12] S. Ordonez, F.V. Dıez, H. Sastre, Catalytic Hydrodechlorination of Chlorinated Olefins over a $\mathrm{Pd} / \mathrm{Al} 2 \mathrm{O} 3$ Catalyst: Kinetics and Inhibition Phenomena, Industrial \& Engineering Chemistry Research, 41 (2002) 7.

[13] K.N. Heck, B.G. Janesko, G.E. Scuseria, N.J. Halas, M.S. Wong, Observing metal-catalyzed chemical reactions in situ using surface-enhanced Raman spectroscopy on Pd-Au nanoshells, Journal of the American Chemical Society, 130 (2008) 16592-16600.

[14] M. Cobo, C.A. González, E.G. Sánchez, C. Montes, Catalytic hydrodechlorination of trichloroethylene with 2-propanol over Pd/AI2O3, Catalysis today, 172 (2011) 78-83.

[15] E. Díaz, A. McCall, L. Faba, H. Sastre, S. Ordóñez, Trichloroethylene hydrodechlorination in water using formic acid as hydrogen source: selection of catalyst and operation conditions, Environmental Progress \& Sustainable Energy, 32 (2013) 1217-1222.

[16] X. Yu, T. Wu, X.-J. Yang, J. Xu, J. Auzam, R. Semiat, Y.-F. Han, Degradation of trichloroethylene by hydrodechlorination using formic acid as hydrogen source over supported Pd catalysts, Journal of hazardous materials, 305 (2016) 178-189.

[17] M. Cobo, J. Becerra, M. Castelblanco, B. Cifuentes, J.A. Conesa, Catalytic hydrodechlorination of trichloroethylene in a novel $\mathrm{NaOH} / 2$-propanol/methanol/water system on ceria-supported Pd and Rh catalysts, Journal of environmental management, 158 (2015) 110.

[18] M. Zhang, D.B. Bacik, C.B. Roberts, D. Zhao, Catalytic hydrodechlorination of trichloroethylene in water with supported CMC-stabilized palladium nanoparticles, Water Research, 47 (2013) 3706-3715.

[19] C.G. Schreier, M. Reinhard, CATALYTIC HYDRODEHALOGENATION OF CHLORINATED ETHYLENES USING PALLADIUM AND HYDROGEN FOR THE TREATMENT OF CONTAMINATED WATER, Chemosphere, 31 (1995) 13.

[20] E. Lopez, S. Ordonez, F. Diez, Deactivation of a Pd/Al2O3 catalyst used in hydrodechlorination reactions: Influence of the nature of organochlorinated compound and hydrogen chloride, Applied Catalysis B: Environmental, 62 (2006) 57-65. 
[21] G.V. Lowry, M. Reinhard, Pd-Catalyzed TCE Dechlorination in Groundwater: Solute Effects, Biological Control, and Oxidative Catalyst Regeneration, Environmental Science \& Technology, 34 (2000) 3217-3223.

[22] G.V. Lowry, M. Reinhard, Pd-catalyzed TCE dechlorination in water: effect of [H2](aq) and $\mathrm{H} 2$-utilizing competitive solutes on the TCE dechlorination rate and product distribution, Environmental science \& technology, 35 (2001) 696-702.

[23] E. López, S. Ordóñez, H. Sastre, F.V. D'ıez, Kinetic study of the gas-phase hydrogenation of aromatic and aliphatic organochlorinated compounds using a Pd/Al2O3 catalyst, Journal of Hazardous Materials, B97 (2003) 14.

[24] F.-D. Kopinke, K. Mackenzie, R. Köhler, Catalytic hydrodechlorination of groundwater contaminants in water and in the gas phase using Pd/ $\mathrm{Y}-\mathrm{Al} 2 \mathrm{O} 3$, Applied Catalysis $\mathrm{B}$ :

Environmental, 44 (2003) 15-24.

[25] R. Navon, S. Eldad, K. Mackenzie, F.-D. Kopinke, Protection of palladium catalysts for hydrodechlorination of chlorinated organic compounds in wastewaters, Applied Catalysis B: Environmental, 119-120 (2012) 241-247.

[26] Y.-L. Fang, K.N. Heck, P.J. Alvarez, M.S. Wong, Kinetics analysis of palladium/gold nanoparticles as colloidal hydrodechlorination catalysts, ACS Catalysis, 1 (2011) 128-138.

[27] B.T. Meshesha, N. Barrabés, J. Llorca, A. Dafinov, F. Medina, K. Föttinger, PdCu alloy nanoparticles on alumina as selective catalysts for trichloroethylene hydrodechlorination to ethylene, Applied Catalysis A: General, 453 (2013) 130-141.

[28] Y. Han, C. Liu, J. Horita, W. Yan, Trichloroethene hydrodechlorination by Pd-Fe bimetallic nanoparticles: Solute-induced catalyst deactivation analyzed by carbon isotope fractionation, Applied Catalysis B: Environmental, 188 (2016) 77-86.

[29] F. He, Z. Li, S. Shi, W. Xu, H. Sheng, Y. Gu, Y. Jiang, B. Xi, Dechlorination of excess

trichloroethene by bimetallic and sulfidated nanoscale zero-valent iron, Environmental science \& technology, 52 (2018) 8627-8637.

[30] J. Andersin, P. Parkkinen, K. Honkala, Pd-catalyzed hydrodehalogenation of chlorinated olefins: Theoretical insights to the reaction mechanism, Journal of Catalysis, 290 (2012) 118125.

[31] K.N. Heck, M.O. Nutt, P. Alvarez, M.S. Wong, Deactivation resistance of Pd/Au nanoparticle catalysts for water-phase hydrodechlorination, Journal of Catalysis, 267 (2009) 97-104.

[32] A. Śrębowata, K. Tarach, V. Girman, K. Góra-Marek, Catalytic removal of trichloroethylene from water over palladium loaded microporous and hierarchical zeolites, Applied Catalysis B:

Environmental, 181 (2016) 550-560.

[33] E. Díaz, L. Faba, S. Ordóñez, Effect of carbonaceous supports on the Pd-catalyzed aqueousphase trichloroethylene hydrodechlorination, Applied Catalysis B: Environmental, 104 (2011) 415-417.

[34] H. Sohn, G. Celik, S. Gunduz, S.S. Majumdar, S.L. Dean, P.L. Edmiston, U.S. Ozkan, Effect of high-temperature on the swellable organically-modified silica (SOMS) and its application to gasphase hydrodechlorination of trichloroethylene, Applied Catalysis B: Environmental, 209 (2017) 80-90.

[35] H. Sohn, G. Celik, S. Gunduz, S.L. Dean, E. Painting, P.L. Edmiston, U.S. Ozkan, Hydrodechlorination of trichloroethylene over Pd supported on swellable organically-modified silica (SOMS), Applied Catalysis B: Environmental, 203 (2017) 641-653. 
[36] G. Celik, S.A. Ailawar, S. Gunduz, J.T. Miller, P.L. Edmiston, U.S. Ozkan, Aqueous-phase hydrodechlorination of trichloroethylene over Pd-based swellable organically-modified silica (SOMS): Catalyst deactivation due to chloride anions, Applied Catalysis B: Environmental, 239 (2018) 654-664.

[37] G. Celik, S.A. Ailawar, S. Gunduz, J.T. Miller, P.L. Edmiston, U.S. Ozkan, Aqueous-Phase Hydrodechlorination of Trichloroethylene over Pd-Based Swellable Organically Modified Silica: Catalyst Deactivation Due to Sulfur Species, Industrial \& Engineering Chemistry Research, 58 (2019) 4054-4064.

[38] G. Celik, S. Ailawar, H. Sohn, Y. Tang, F. Tao, J.T. Miller, P.L. Edmiston, U.S. Ozkan, Swellable Organically-modified Silica (SOMS) as a Catalyst Scaffold for Catalytic Treatment of Water Contaminated with Trichloroethylene, ACS Catalysis, (2018).

[39] G. Celik, S.A. Ailawar, S. Gunduz, P.L. Edmiston, U.S. Ozkan, Formation of carbonaceous deposits on Pd-based hydrodechlorination catalysts: Vibrational spectroscopy investigations over Pd/Al2O3 and Pd/SOMS, Catalysis Today, (2018).

[40] P.L. Edmiston, L.A. Underwood, Absorption of dissolved organic species from water using organically modified silica that swells, Separation and Purification Technology, 66 (2009) 532540.

[41] C.M. Burkett, L.A. Underwood, R.S. Volzer, J.A. Baughman, P.L. Edmiston, OrganicInorganic Hybrid Materials that Rapidly Swell in Non-Polar Liquids: Nanoscale Morphology and Swelling Mechanism, Chemistry of Materials, 20 (2008) 1312-1321.

[42] C.M. Burkett, P.L. Edmiston, Highly swellable sol-gels prepared by chemical modification of silanol groups prior to drying, Journal of Non-Crystalline Solids, 351 (2005) 3174-3178. [43] P.L. Edmiston, L.J. West, A. Chin, N. Mellor, D. Barth, Adsorption of Gas Phase Organic Compounds by Swellable Organically Modified Silica, Industrial \& Engineering Chemistry Research, 55 (2016) 12068-12079.

[44] E.K. Stebel, K.A. Pike, H. Nguyen, H.A. Hartmann, M.J. Klonowski, M.G. Lawrence, R.M. Collins, C.E. Hefner, P.L. Edmiston, Absorption of short-chain to long-chain perfluoroalkyl substances using swellable organically modified silica, Environmental Science: Water Research \& Technology, 5 (2019) 1854-1866.

[45] S. Ailawar, A. Hunoor, Y. Khalifa, J.T. Miller, P.L. Edmiston, U.S. Ozkan, Elucidating the Role of Ethanol in Aqueous Phase Hydrodechlorination of Trichloroethylene over Pd Catalysts Supported on Swellable Organically Modified Silica (SOMS), Applied Catalysis B: Environmental, (2020) 119819.

[46] L. Zwank, T.C. Schmidt, S.B. Haderlein, M. Berg, Simultaneous determination of fuel oxygenates and BTEX using direct aqueous injection gas chromatography mass spectrometry (DAI-GC/MS), Environmental science \& technology, 36 (2002) 2054-2059.

[47] C.A. Schneider, W.S. Rasband, K.W. Eliceiri, NIH Image to ImageJ: 25 years of image analysis, Nature methods, 9 (2012) 671-675.

[48] S. Brunauer, P.H. Emmett, E. Teller, Adsorption of gases in multimolecular layers, Journal of the American chemical society, 60 (1938) 309-319.

[49] E.P. Barrett, L.G. Joyner, P.P. Halenda, The determination of pore volume and area distributions in porous substances. I. Computations from nitrogen isotherms, Journal of the American Chemical society, 73 (1951) 373-380. 
[50] V.F. Kispersky, A.J. Kropf, F.H. Ribeiro, J.T. Miller, Low absorption vitreous carbon reactors for operando XAS: a case study on $\mathrm{Cu} /$ Zeolites for selective catalytic reduction of $\mathrm{NO} \times$ by $\mathrm{NH} 3$, Physical Chemistry Chemical Physics, 14 (2012) 2229-2238.

[51] B.R. Fingland, F.H. Ribeiro, J.T. Miller, Simultaneous measurement of X-ray absorption spectra and kinetics: a fixed-bed, plug-flow operando reactor, Catalysis letters, 131 (2009) 1-6. [52] C. Segre, N. Leyarovska, L. Chapman, W. Lavender, P. Plag, A. King, A. Kropf, B. Bunker, K. Kemner, P. Dutta, The MRCAT insertion device beamline at the Advanced Photon Source, in: AIP Conference Proceedings, American Institute of Physics, 2000, pp. 419-422. [53] A. Kropf, J. Katsoudas, S. Chattopadhyay, T. Shibata, E. Lang, V. Zyryanov, B. Ravel, K. Mclvor, K. Kemner, K. Scheckel, The new MRCAT (Sector 10) bending magnet beamline at the advanced photon source, in: AIP Conference Proceedings, American Institute of Physics, 2010, pp. 299-302.

[54] T. Ressler, WinXAS: A new software package not only for the analysis of energy-dispersive XAS data, Le Journal de Physique IV, 7 (1997) C2-269-C262-270.

[55] M. Thommes, K. Kaneko, A.V. Neimark, J.P. Olivier, F. Rodriguez-Reinoso, J. Rouquerol, K.S. Sing, Physisorption of gases, with special reference to the evaluation of surface area and pore size distribution (IUPAC Technical Report), Pure and Applied Chemistry, 87 (2015) 1051-1069. [56] D. Basu, S. Ailawar, G. Celik, P. Edmiston, U.S. Ozkan, Effect of high temperature on swellable organically modified silica (SOMS) and its application for preferential CO oxidation in $\mathrm{H} 2$ rich environment, ChemCatChem, $\mathrm{n} / \mathrm{a}$.

[57] J.C. Groen, L.A. Peffer, J. Pérez-Ramírez, Pore size determination in modified micro-and mesoporous materials. Pitfalls and limitations in gas adsorption data analysis, Microporous and mesoporous materials, 60 (2003) 1-17.

[58] R.J. Madon, M. Boudart, Experimental criterion for the absence of artifacts in the measurement of rates of heterogeneous catalytic reactions, Industrial \& Engineering Chemistry Fundamentals, 21 (1982) 438-447.

[59] U.K. Singh, M.A. Vannice, Liquid-phase hydrogenation of citral over Pt/SiO2 catalysts: i. Temperature effects on activity and selectivity, Journal of Catalysis, 191 (2000) 165-180. [60] M. Zecca, P. Centomo, B. Corain, Metal nanoclusters supported on cross-linked functional polymers: a class of emerging metal catalysts, Metal Nanoclusters in Catalysis and Materials Science; Corain, B., Schmid, G., Toshima, N., Eds, (2008) 201-232.

[61] A. Biffis, H. Landes, K. Jeřábek, B. Corain, Metal palladium dispersed inside macroporous ion-exchange resins: the issue of the accessibility to gaseous reactants, Journal of Molecular Catalysis A: Chemical, 151 (2000) 283-288.

[62] R.P. Schwarzenbach, P.M. Gschwend, D.M. Imboden, Environmental organic chemistry, John Wiley \& Sons, 2016.

[63] M.L. Toebes, J.A. van Dillen, K.P. de Jong, Synthesis of supported palladium catalysts, Journal of Molecular Catalysis A: Chemical, 173 (2001) 75-98.

[64] C.W. Lopes, J.L. Cerrillo, A.E. Palomares, F. Rey, G. Agostini, An in situ XAS study of the activation of precursor-dependent Pd nanoparticles, Physical Chemistry Chemical Physics, 20 (2018) 12700-12709.

[65] C. Keresszegi, J.-D. Grunwaldt, T. Mallat, A. Baiker, In situ EXAFS study on the oxidation state of $\mathrm{Pd} / \mathrm{Al} 2 \mathrm{O} 3$ and $\mathrm{Bi}-\mathrm{Pd} / \mathrm{Al} 2 \mathrm{O} 3$ during the liquid-phase oxidation of 1-phenylethanol, Journal of Catalysis, 222 (2004) 268-280. 
[66] N.M. Martin, J. Nilsson, M. Skoglundh, E.C. Adams, X. Wang, P. Velin, G. Smedler, A. Raj, D. Thompsett, H.H. Brongersma, Characterization of Surface Structure and Oxidation/Reduction Behavior of Pd-Pt/Al2O3 Model Catalysts, The Journal of Physical Chemistry C, 120 (2016) 28009-28020.

[67] Purwanto, R. Deshpande, R. Chaudhari, H. Delmas, Solubility of hydrogen, carbon monoxide, and 1-octene in various solvents and solvent mixtures, Journal of Chemical \& Engineering Data, 41 (1996) 1414-1417.

[68] M.A. Newton, R. Nicholls, J.B. Brazier, B.N. Nguyen, C.J. Mulligan, K. Hellgardt, E.M. Barreiro, H. Emerich, K.K. Hii, I. Snigireva, P.B.J. Thompson, Effect of retained chlorine in ENCAT $^{\text {TM }} 30$ catalysts on the development of encapsulated Pd: insights from in situ Pd K, L3 and Cl K-edge XAS, Catalysis, Structure \& Reactivity, 3 (2017) 149-156. 
Table 1: Effect of metal loading on textural properties of Pd impregnated SOMS

$\begin{array}{cccc}\text { Sample } & \begin{array}{c}\text { BET Surface } \\ \text { Area } \\ \left(\mathbf{m}^{\mathbf{2}} / \mathbf{g}\right)\end{array} & \begin{array}{c}\text { Pore volume } \\ \left(\mathbf{c m}^{\mathbf{3}} / \mathbf{g}\right)\end{array} & \begin{array}{c}\text { Average Pore } \\ \text { size } \\ (\mathbf{n m})\end{array} \\ \text { SOMS } & 615 & 0.9 & 5.4 \\ 0.5 \% \mathrm{Pd} / \mathrm{SOMS} & 513 & 0.6 & 3.7 \\ 1 \% \mathrm{Pd} / \mathrm{SOMS} & 589 & 0.7 & 3.9 \\ 1.5 \% \mathrm{Pd} / \mathrm{SOMS} & 560 & 0.6 & 3.7\end{array}$


Table 2: EXAFS fitting results for effect of $\mathrm{HCl}$ soaking on $\mathrm{Pd} / \mathrm{SOMS}$ in TCE and ethanol containing solutions

\begin{tabular}{|c|c|c|c|c|c|c|}
\hline Sample & $\begin{array}{c}\mathbf{E}_{\mathbf{0}} \\
\text { Threshold } \\
\text { energy }(\mathrm{eV})\end{array}$ & $\begin{array}{c}\text { Scattering } \\
\text { Path }\end{array}$ & $\begin{array}{c}\mathrm{CN} \\
\text { Coordination } \\
\text { number }\end{array}$ & $\underset{(\stackrel{\mathbf{A}}{)})}{\mathbf{R}}$ & $\begin{array}{c}\Delta \sigma^{2} \\
\left(\AA^{2}\right) \times 10^{3}\end{array}$ & $\begin{array}{c}\mathrm{E}_{\mathbf{0}} \text {-shift } \\
(\mathrm{eV})\end{array}$ \\
\hline $\begin{array}{l}\mathrm{Pd} / \mathrm{SOMS} \\
\text { pristine }\end{array}$ & 24350.5 & $\mathrm{Pd}-\mathrm{Pd}$ & 8.5 & 2.74 & 3.5 & -1.7 \\
\hline & \multirow[t]{2}{*}{24352.5} & $\mathrm{Pd}-\mathrm{Pd}$ & 6.5 & 2.75 & 1.5 & -2.2 \\
\hline $\mathrm{HCl}$ TCE & & $\mathrm{Pd}-\mathrm{Cl}$ & 2.1 & 2.30 & 4.5 & 0.3 \\
\hline \multirow{2}{*}{$\begin{array}{l}\text { Pd/SOMS } 0.2 \mathrm{M} \\
\text { HCl TCE } 10 \%\end{array}$} & \multirow[b]{2}{*}{24352} & $\mathrm{Pd}-\mathrm{Pd}$ & 7.2 & 2.76 & 2.5 & -3.3 \\
\hline & & $\mathrm{Pd}-\mathrm{Cl}$ & 1.2 & 2.33 & 4.0 & 3.2 \\
\hline
\end{tabular}



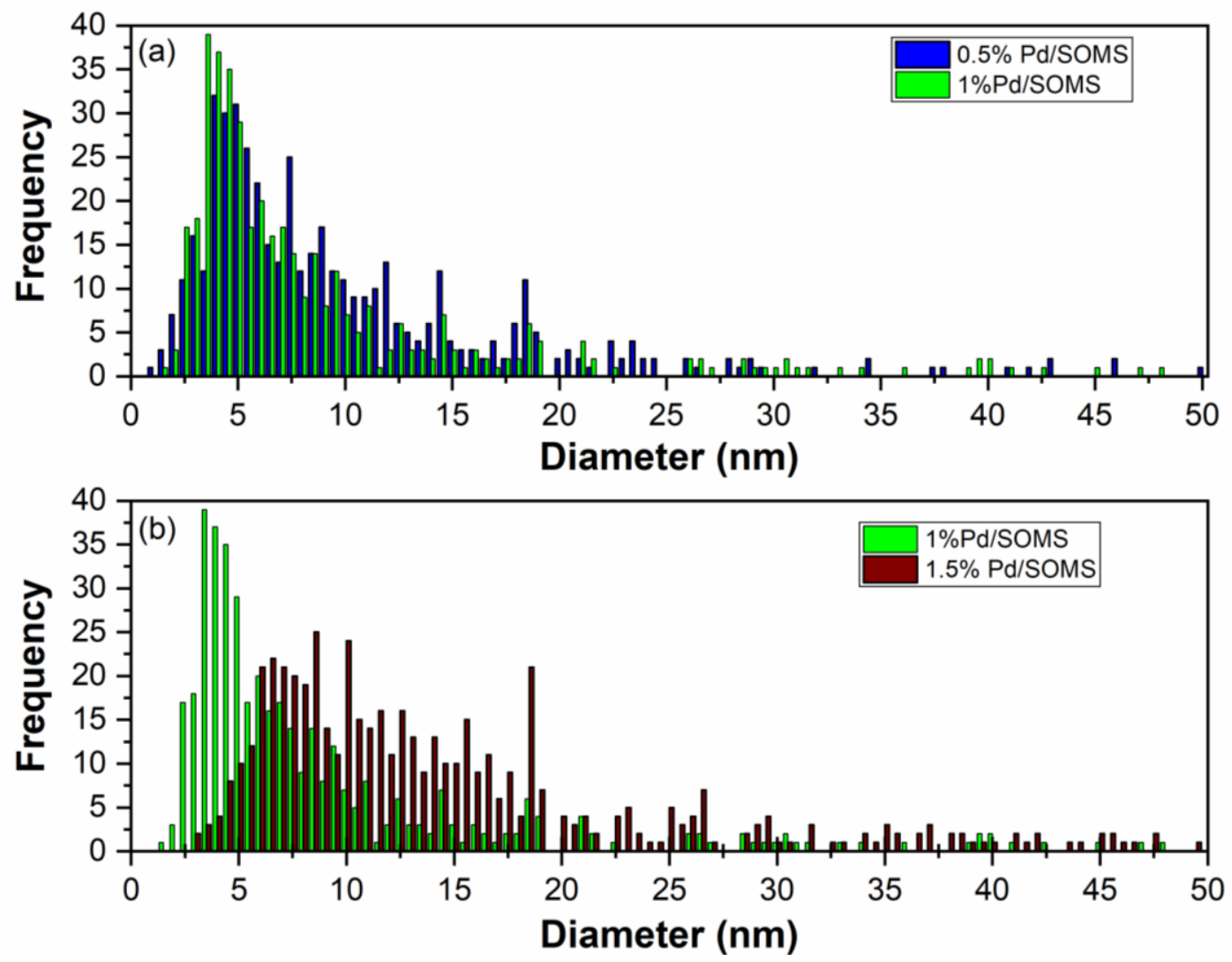

Figure 1: Comparison of the particle size distribution measured for (a) $0.5 \% \mathrm{Pd} / \mathrm{SOMS}$ and $1 \% \mathrm{Pd} / \mathrm{SOMS}$ (b) $1 \% \mathrm{Pd} / \mathrm{SOMS}$ and $1.5 \% \mathrm{Pd} / \mathrm{SOMS}$ 


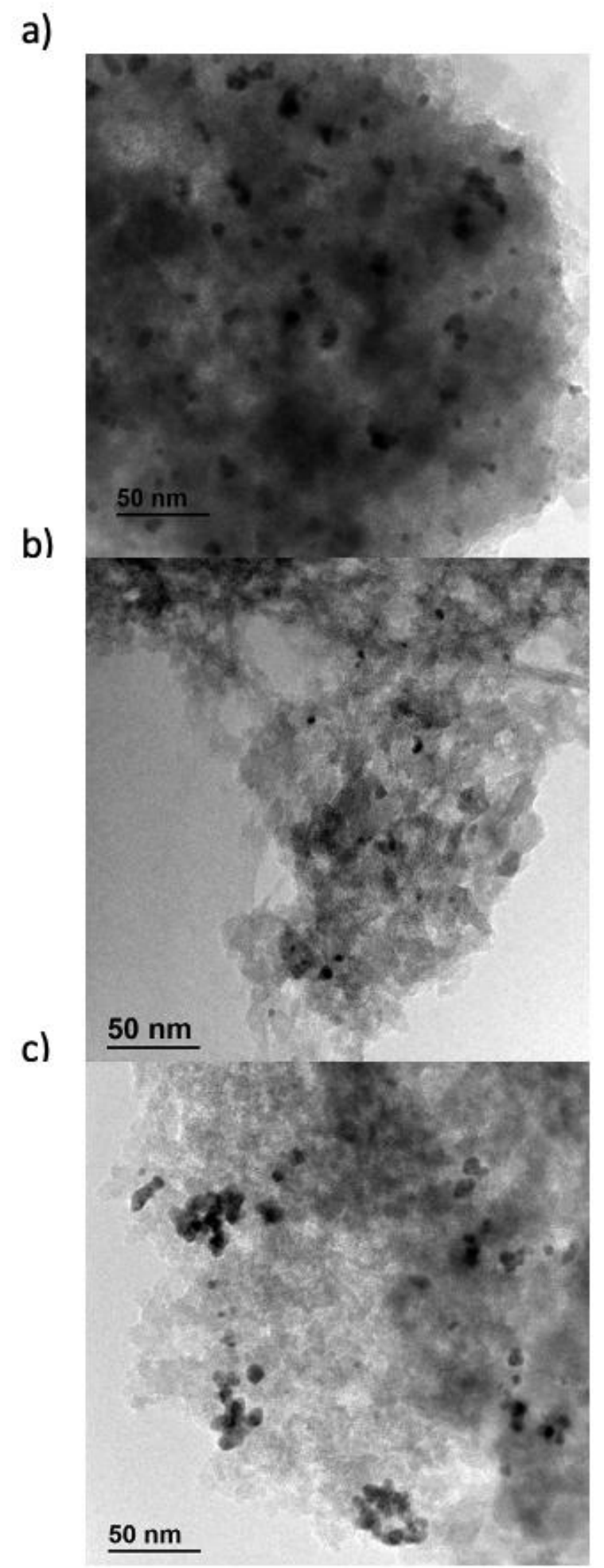

Figure 2: TEM images showing the distribution of Pd particles supported on SOMS with a loading of (a) $0.5 \%$ (b) $1 \%$ (c) $1.5 \%$ wt loadings 

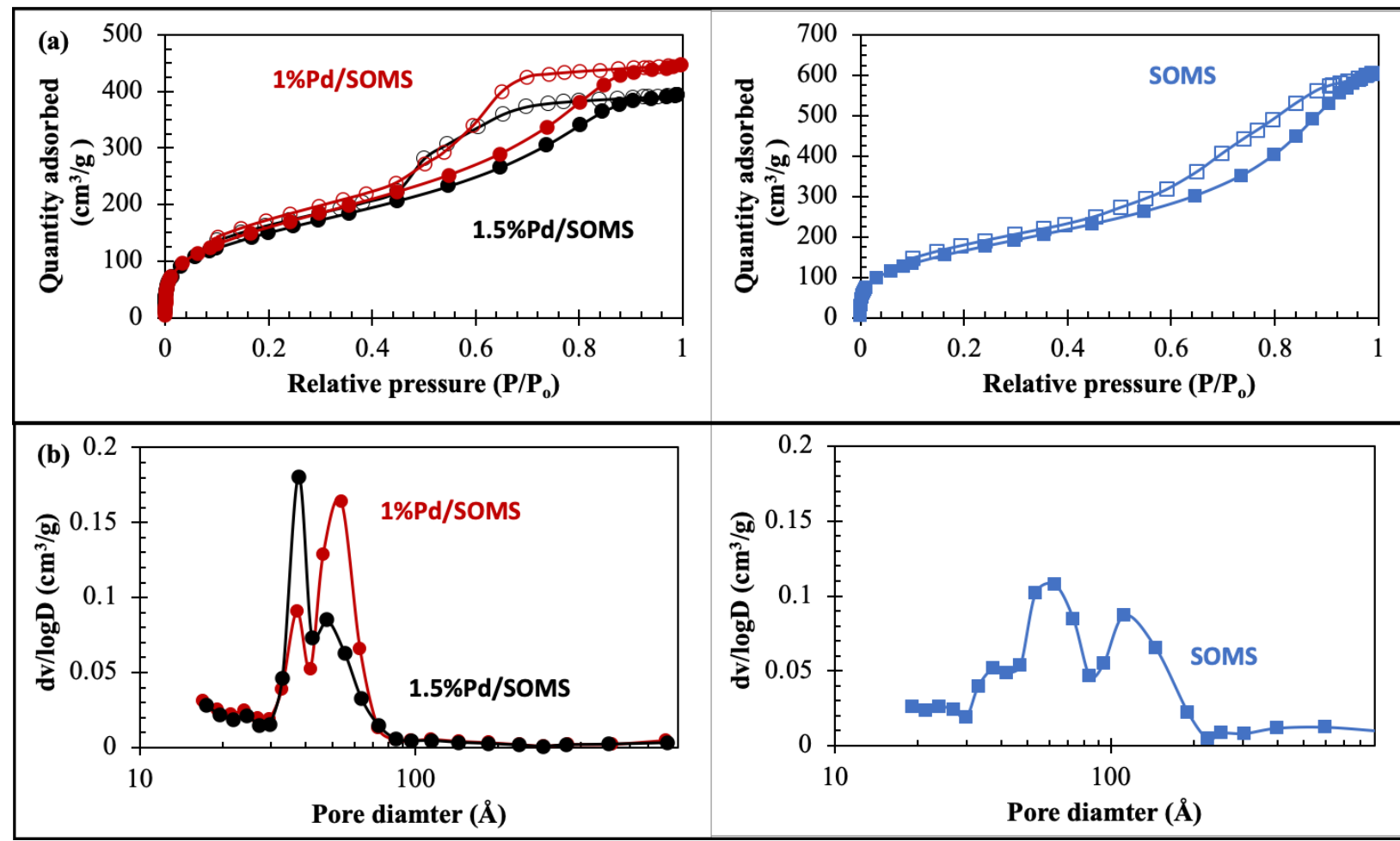

Figure 3: Textural properties of SOMS, $1 \% \mathrm{Pd} / \mathrm{SOMS}$ and $1.5 \% \mathrm{Pd} / \mathrm{SOMS}$, (a) $\mathrm{N}_{2}$ adsorptiondesorption isotherm; (b) $\mathrm{BJH}$ pore size distribution 
(a)
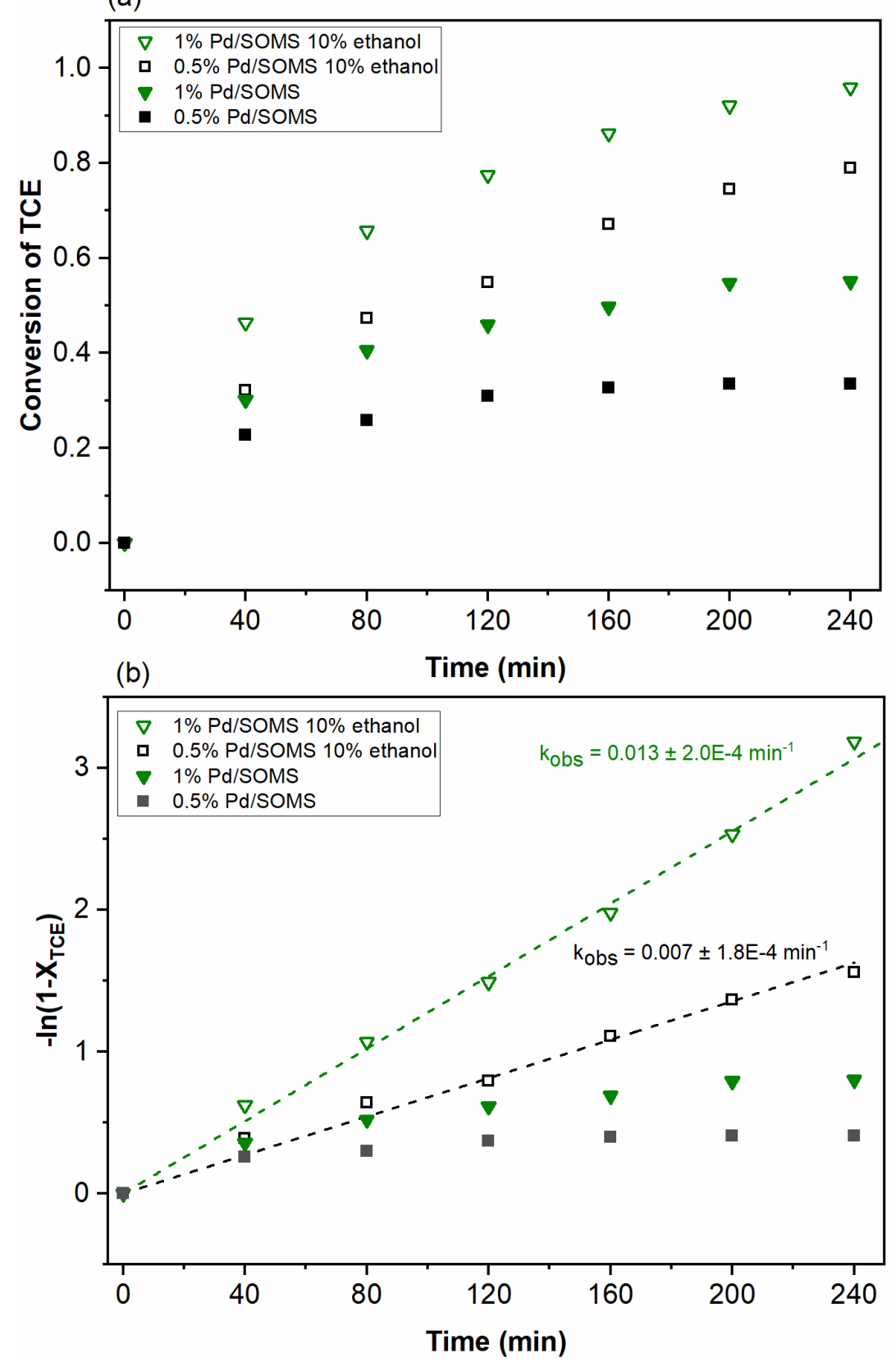

Figure 4: Effect of metal loading on HDC of TCE in the presence and absence of ethanol;

(a) Conversion vs time (b) Linearized plots of TCE conversion $\left(\mathrm{X}_{\mathrm{TCE}}\right)$ vs time 


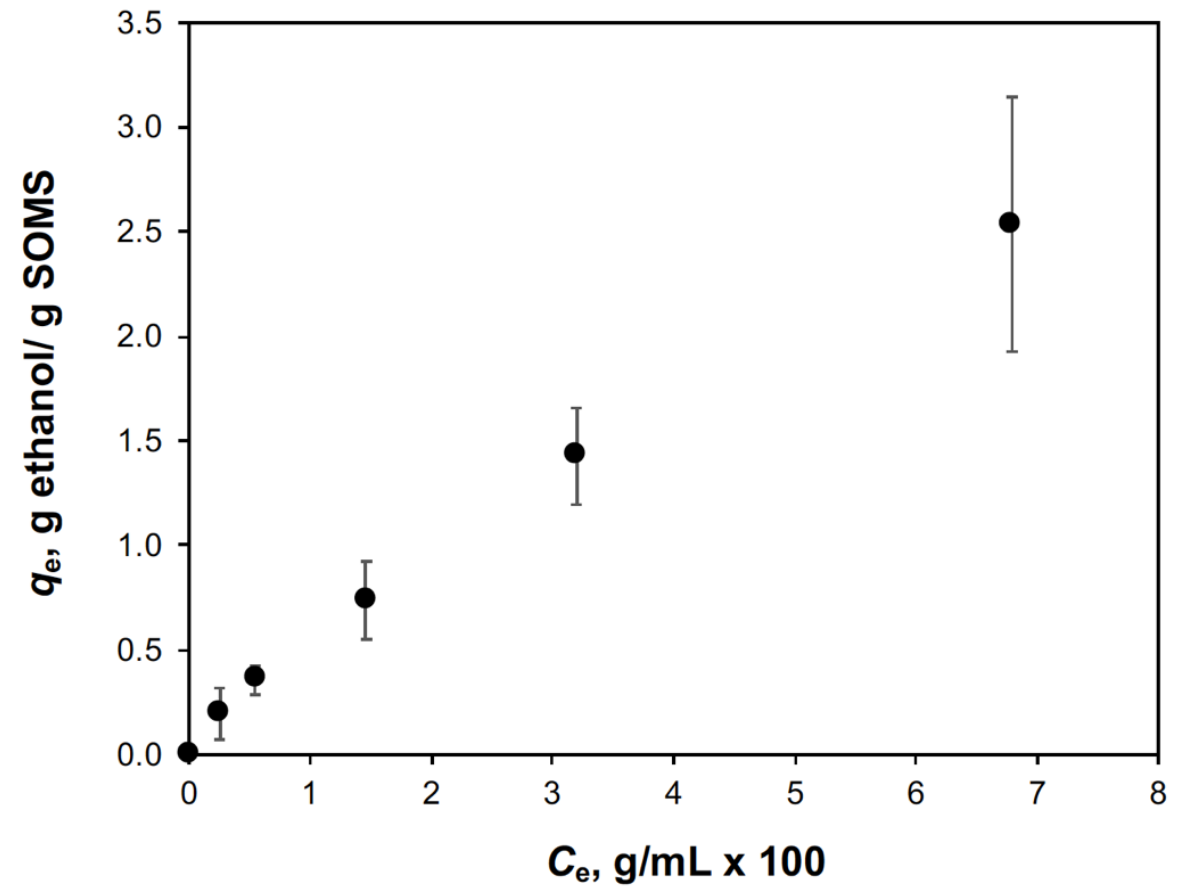

Figure 5: Adsorption isotherm of ethanol on SOMS at room temperature where $\mathrm{q}_{\mathrm{e}}$ is the amount of ethanol absorbed by $1 \mathrm{~g}$ of SOMS 

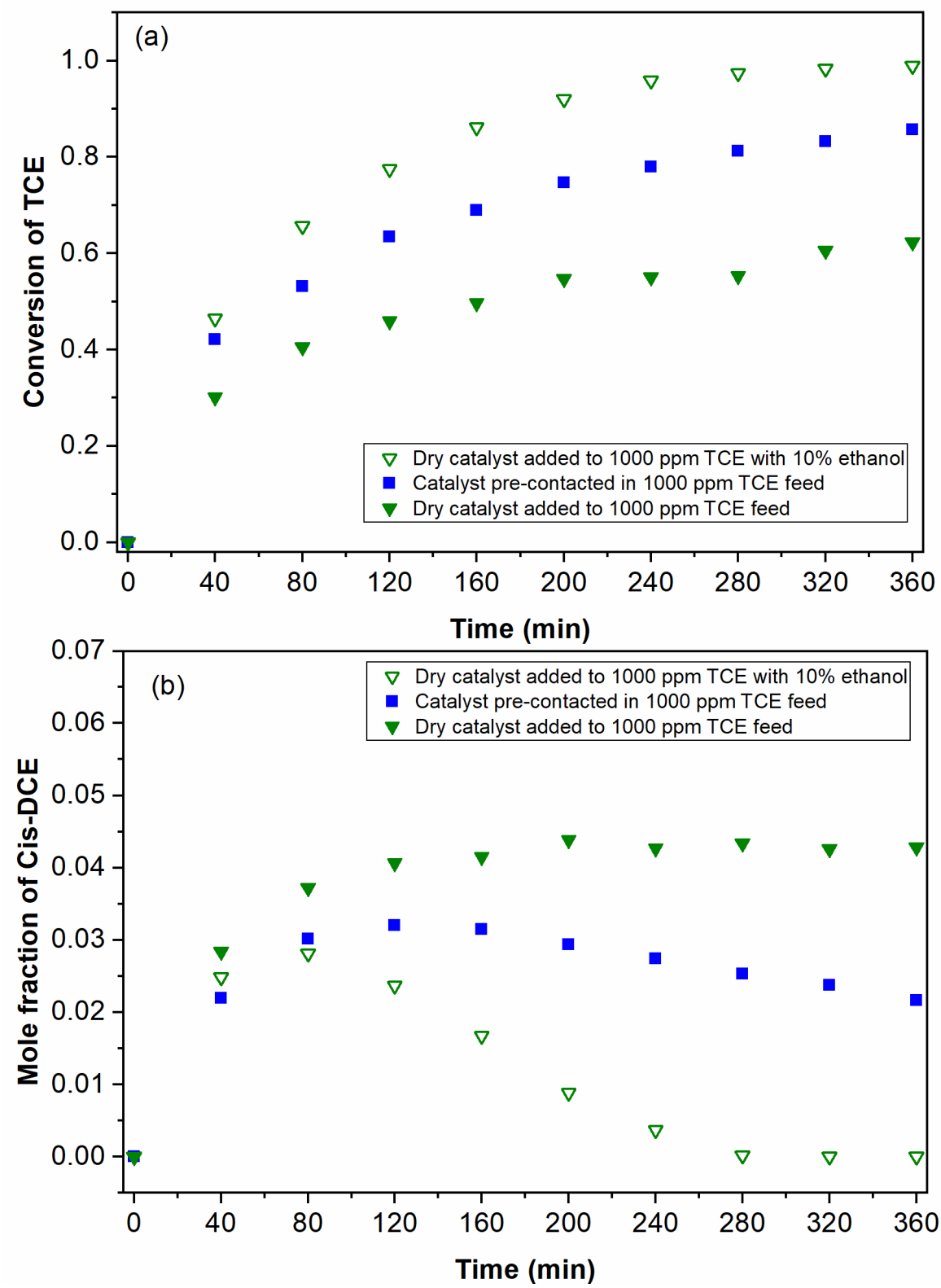

Figure 6: Effect of pre-contacting 1\% Pd/SOMS with TCE; at $30{ }^{\circ} \mathrm{C}, 50$ bar $\mathrm{H}_{2}, 25 \mathrm{mg} / \mathrm{L}$ of catalyst; a) Conversion of TCE vs time b) Mole fraction of cis-dichloroethylene (cis-DCE) where mole fraction is defined as $\frac{\text { moles of cis-DCE }}{\text { moles of all chlorinated species }}$ 

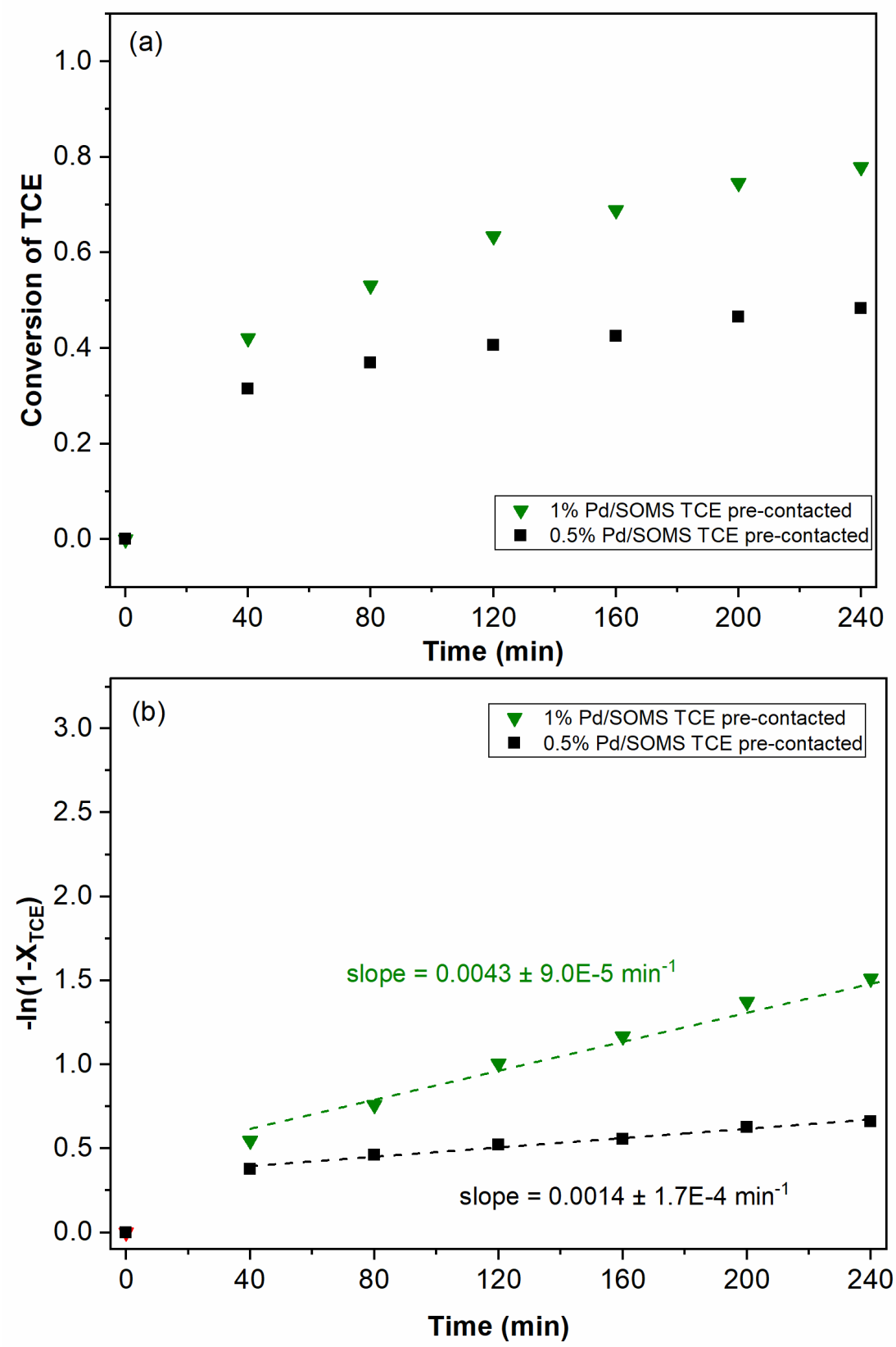

Figure 7: Effect of metal loading while pre-contacting Pd/SOMS with TCE; at $30{ }^{\circ} \mathrm{C}, 50 \mathrm{bar}_{2}$, $25 \mathrm{mg} / \mathrm{L}$ of catalyst; a) Conversion of TCE vs time b) Linearized plot of TCE conversion $\left(\mathrm{X}_{\mathrm{TCE}}\right)$ vs time 


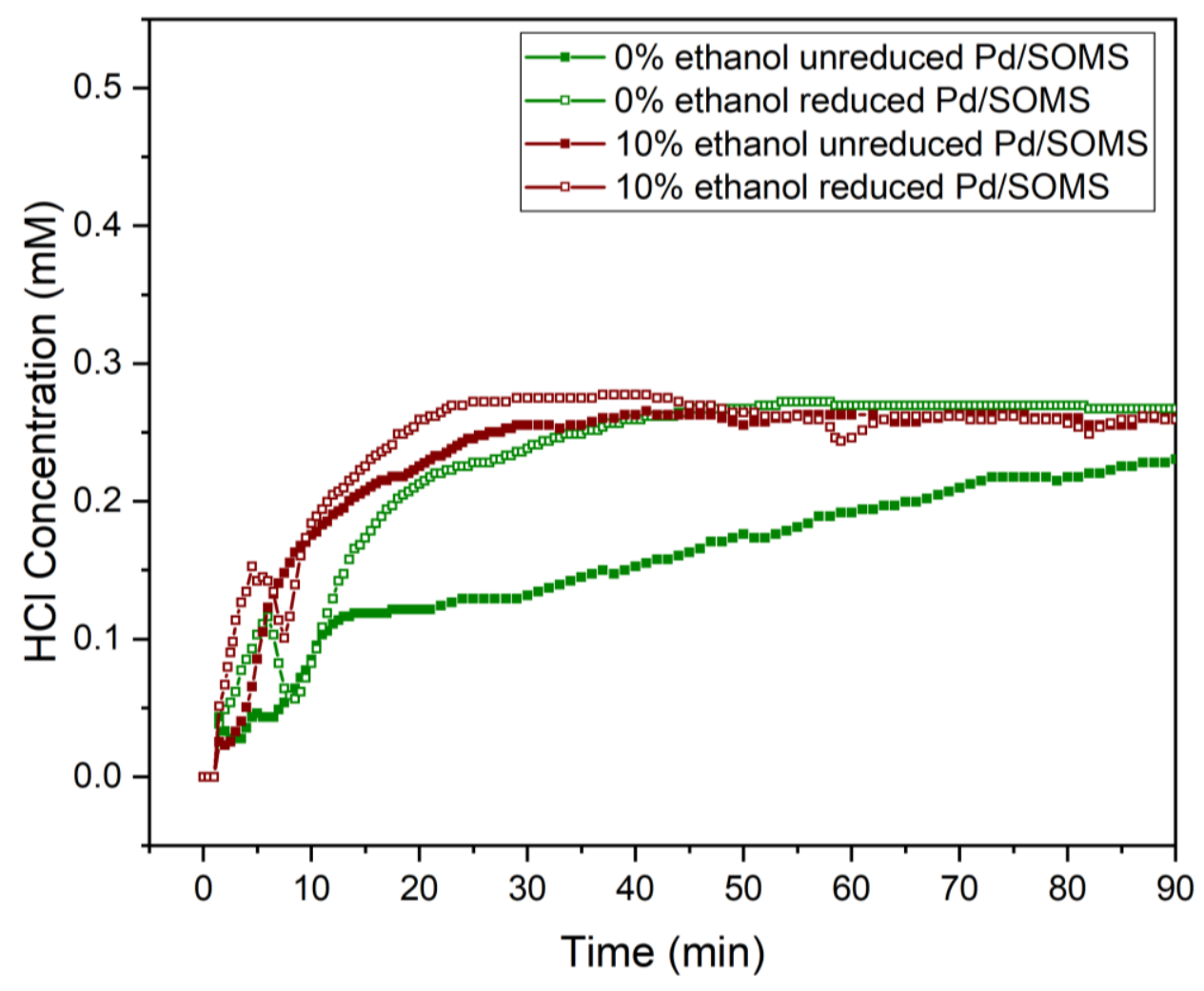

Figure 8: $\mathrm{HCl}$ evolution during $\mathrm{HDC}$ of TCE performed at room temperature and ambient pressure in a flow reactor system; $\mathrm{NaBH}_{4}$ reduction was used for pre-reduced catalyst; $30 \mathrm{mg}$ of $1 \% \mathrm{Pd} / \mathrm{SOMS} ; 1 \mathrm{ml} / \mathrm{min}$ of feed containing $\left[\mathrm{H}_{2}\right] /[\mathrm{TCE}]=5$ 


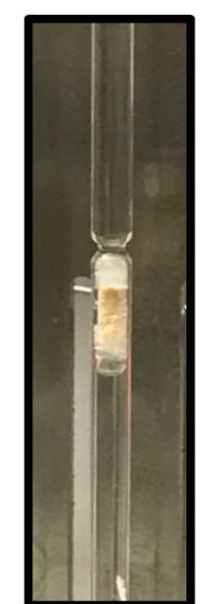

Time: 0 min

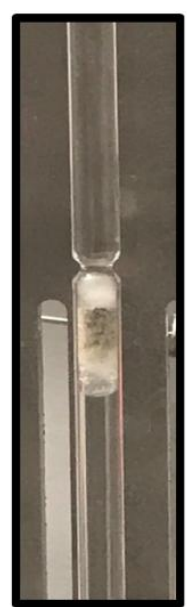

Time: $\mathbf{2 6} \mathbf{~ m i n}$

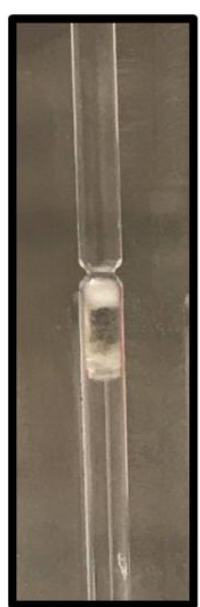

Time: $\mathbf{4 4} \mathrm{min}$

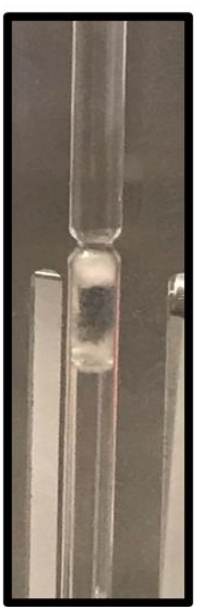

Time: $62 \mathrm{~min}$

Figure 9: Visual changes occurring during HDC of TCE in absence of ethanol starting with unreduced $30 \mathrm{mg}$ of $1 \% \mathrm{Pd} / \mathrm{SOMS} ; 1 \mathrm{ml} / \mathrm{min}$ of feed containing $\left[\mathrm{H}_{2}\right] /[\mathrm{TCE}]=5$ 


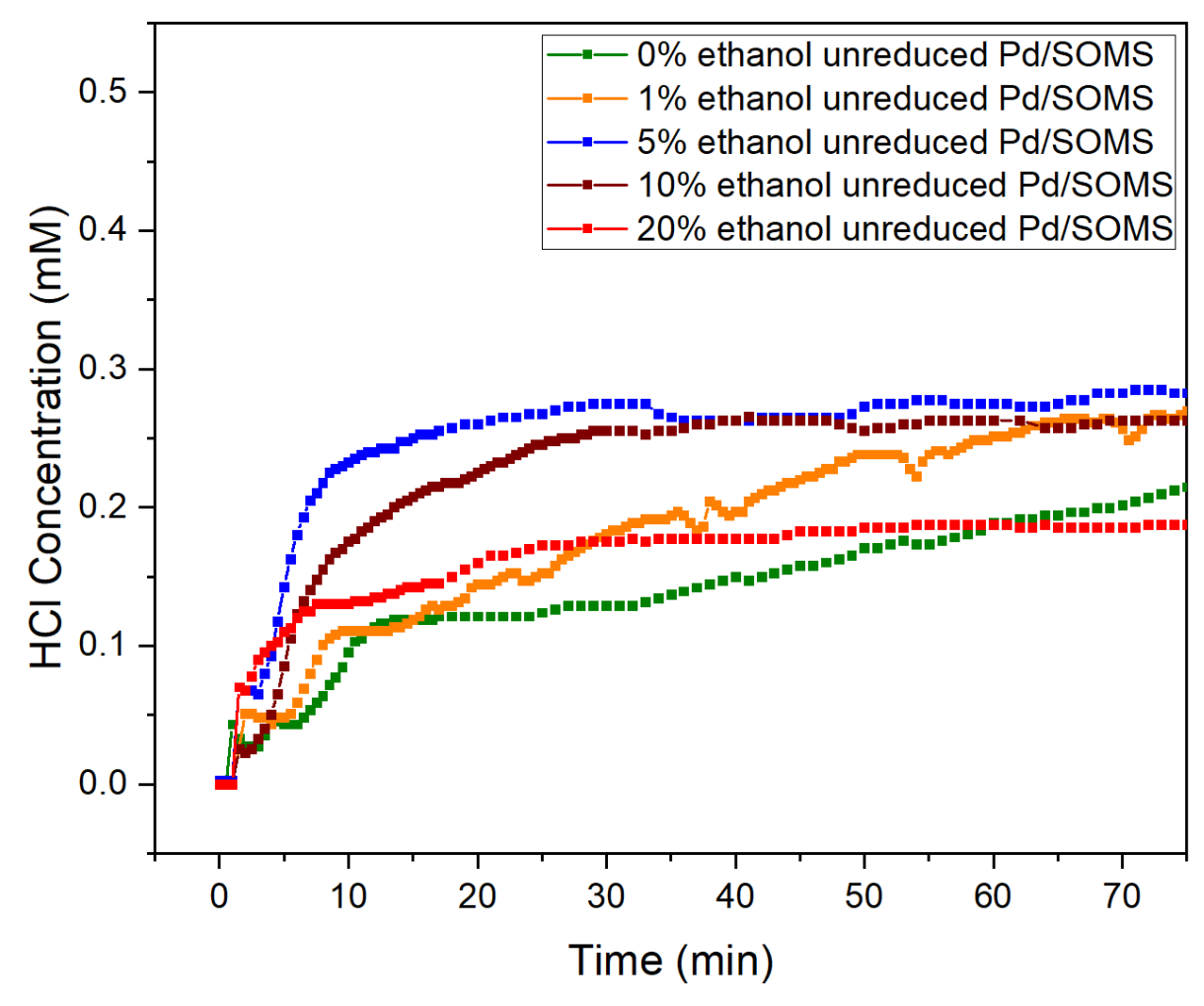

Figure 10: Effect of concentration of ethanol on $\mathrm{HCl}$ evolution during HDC of TCE performed at room temperature and ambient pressure in a flow reactor system with $30 \mathrm{mg}$ of unreduced $1 \% \mathrm{Pd} / \mathrm{SOMS} ; 1 \mathrm{~mL} / \mathrm{min}$ of feed stream containing $\left[\mathrm{H}_{2}\right] /[\mathrm{TCE}]=5$ 

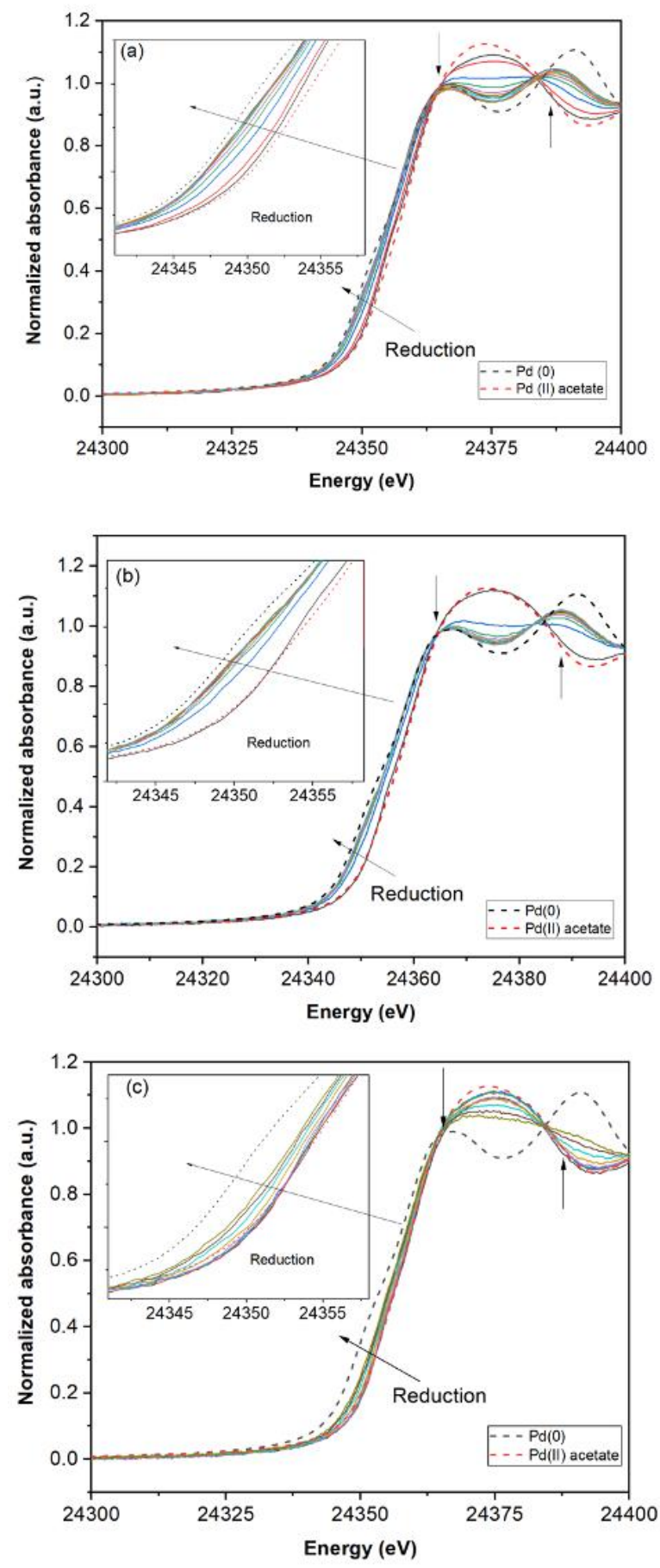

Figure 11: In-situ XANES spectra collected during reduction of Pd acetate/SOMS under ambient conditions: a) $\mathrm{H}_{2}$ dissolved in water; b) $\mathrm{H}_{2}$ dissolved in 5\% ethanol; c) $5 \%$ ethanol without $\mathrm{H}_{2}$. Solid lines represent sample; Dotted lines represent the standards; $30 \mathrm{mg}$ of unreduced $1 \% \mathrm{Pd} / \mathrm{SOMS}$ with $1 \mathrm{ml} / \mathrm{min}$ of feed (saturated with $\mathrm{H}_{2}$ when $\mathrm{H}_{2}$ was used) 

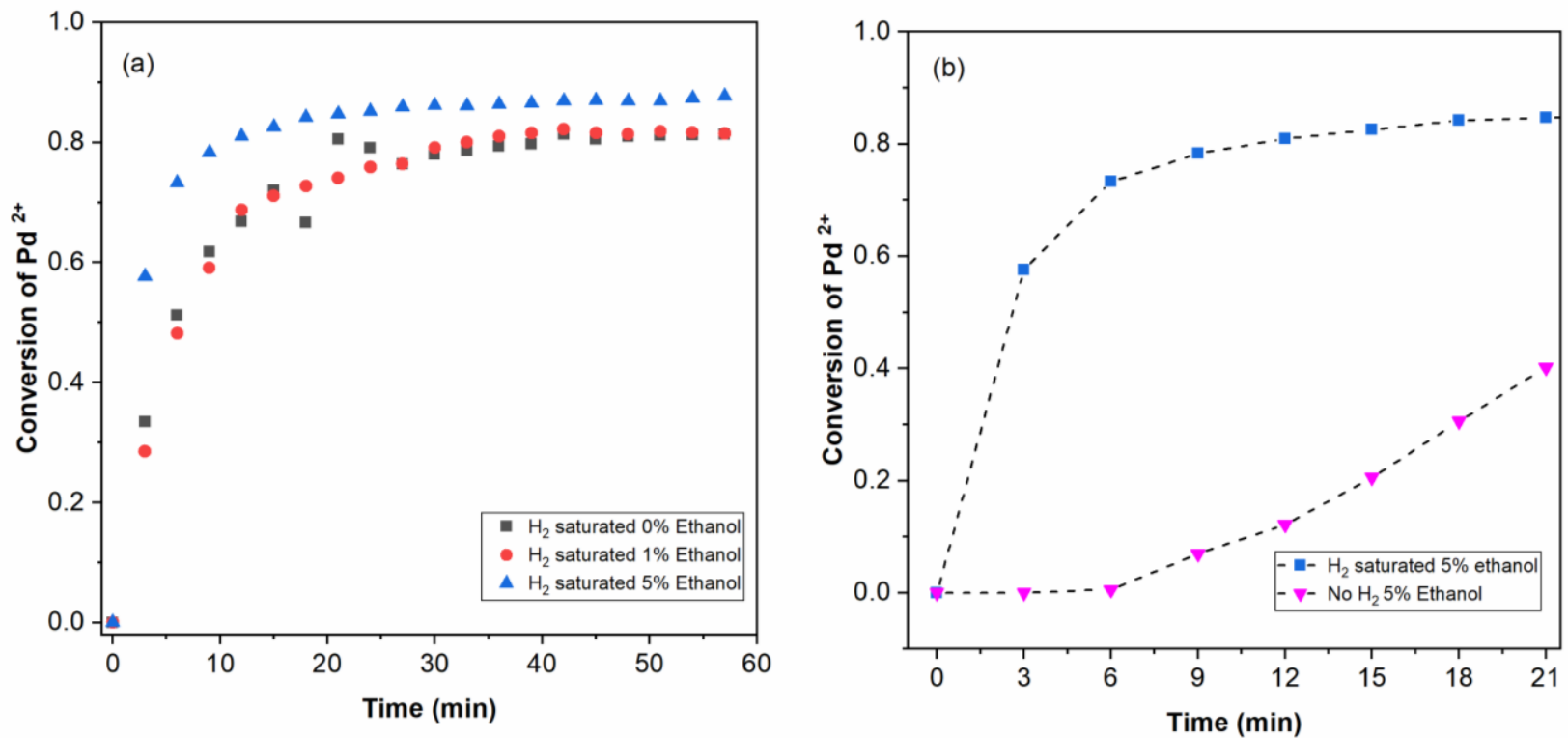

Figure 12: In-situ reduction profile of Pd acetate impregnated on SOMS (a) Effect of ethanol

concentration on reduction with dissolved $\mathrm{H}_{2}$; (b) Effect of presence and absence of $\mathrm{H}_{2}$ on reduction with $5 \%$ ethanol 


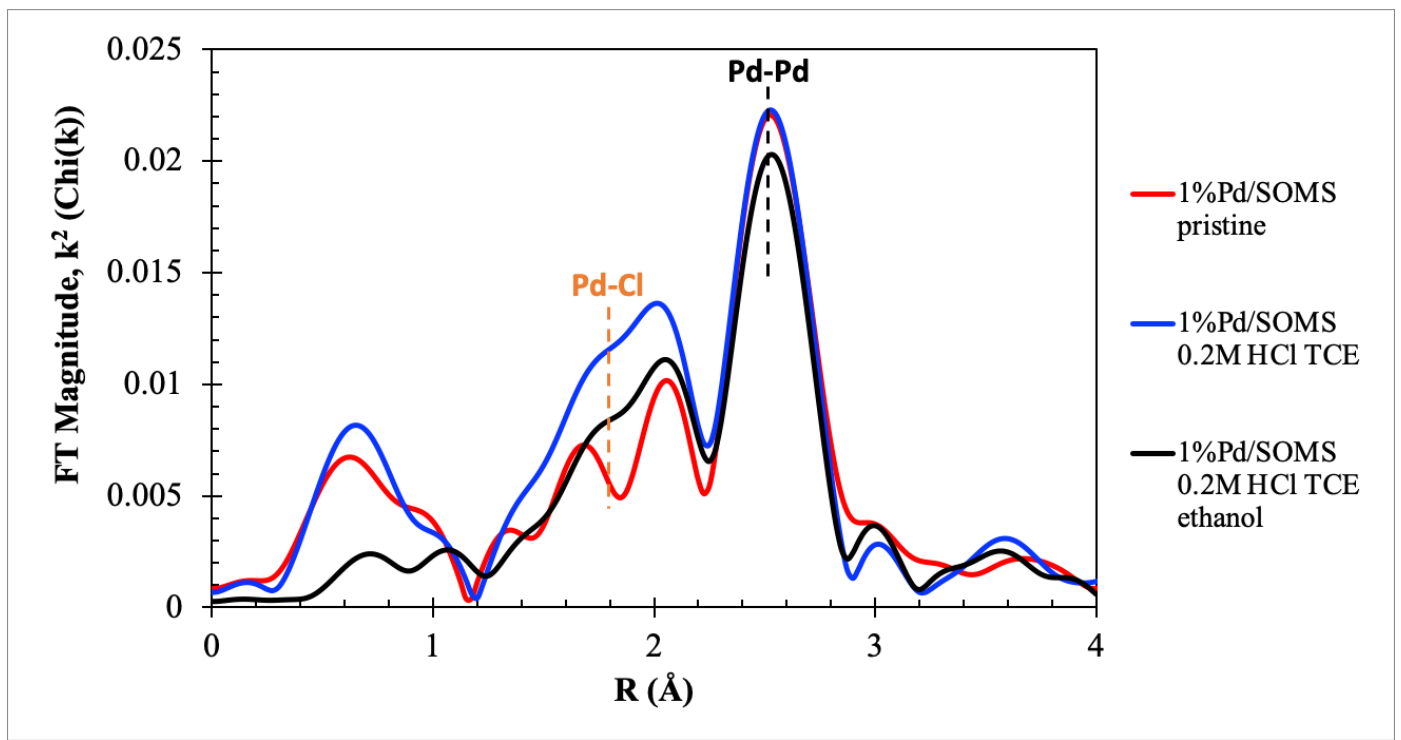

Figure 13: Changes in the atomic environment of Pd supported on SOMS after soaking in $0.2 \mathrm{M}$ $\mathrm{HCl}$ containing aqueous solution of TCE in presence and absence of ethanol 